\title{
Universiteit
}

Leiden

The Netherlands

\section{Six modes of co-production for sustainability}

Chambers, J.M.; Wyborn, C.; Ryan, M.E.; Reid, R.S.; Riechers, M.; Serban, A.; ... ;

Pickering, T.

\section{Citation}

Chambers, J. M., Wyborn, C., Ryan, M. E., Reid, R. S., Riechers, M., Serban, A., ...

Pickering, T. (2021). Six modes of co-production for sustainability. Nature Sustainability, 2021(4), 983-996. doi:10.1038/s41893-021-00755-x

Version: $\quad$ Corrected Publisher's Version

License: $\quad$ Leiden University Non-exclusive license

Downloaded from: https://hdl.handle.net/1887/3249881

Note: To cite this publication please use the final published version (if applicable). 


\title{
Six modes of co-production for sustainability
}

\author{
Josephine M. Chambers ${ }^{1}{ }^{1,2,3} \bowtie$, Carina Wyborn ${ }^{2}{ }^{2,4}$, Melanie E. Ryan ${ }^{(12}{ }^{2}$, Robin S. Reid ${ }^{5}$, \\ Maraja Riechers ${ }^{6}$, Anca Serban ${ }^{2}$, Nathan J. Bennett ${ }^{7,8}$, Christopher Cvitanovic ${ }^{9,10}$, \\ María E. Fernández-Giménez ${ }^{11}$, Kathleen A. Galvinn" ${ }^{12}$, Bruce E. Goldstein ${ }^{13}$, Nicole L. Klenk (1) ${ }^{14}$, \\ Maria Tengö ${ }^{15}$, Ruth Brennan ${ }^{16}$, Jessica J. Cockburn $\left(17\right.$, Rosemary Hill ${ }^{17}{ }^{18,19}$, Claudia Munera (1) 20 , \\ Jeanne L. Nel ${ }^{21,22}$, Henrik Österblom ${ }^{15}$, Angela T. Bednarek ${ }^{23}$, Elena M. Bennett ${ }^{24}$, Amos Brandeis ${ }^{25}$, \\ Lakshmi Charli-Joseph (1026, Paul Chatterton ${ }^{27}$, K. Curran ${ }^{23}$, Pongchai Dumrongrojwatthana ${ }^{28}$, \\ América Paz Durán ${ }^{29,30}$, Salamatu J. Fada ${ }^{31,32}$, Jean-David Gerber ${ }^{10}{ }^{33}$, Jonathan M. H. Green $\mathbb{1}^{34}$, \\ Angela M. Guerrero ${ }^{15}$, Tobias Haller ${ }^{35}$, Andra-loana Horcea-Milcu ${ }^{36}$, Beria Leimona ${ }^{37}$, \\ Jasper Montana $\mathbb{1}^{38}$, Renee Rondeau ${ }^{39}$, Marja Spierenburg ${ }^{40,41}$, Patrick Steyaert ${ }^{42}$, \\ Julie G. Zaehringer ${ }^{43}$, Rebecca Gruby ${ }^{44}$, Jon Hutton ${ }^{2,45}$ and Tomas Pickering ${ }^{46}$
}

The promise of co-production to address complex sustainability challenges is compelling. Yet, co-production, the collaborative weaving of research and practice, encompasses diverse aims, terminologies and practices, with poor clarity over their implications. To explore this diversity, we systematically mapped differences in how 32 initiatives from 6 continents co-produce diverse outcomes for the sustainable development of ecosystems at local to global scales. We found variation in their purpose for utilizing co-production, understanding of power, approach to politics and pathways to impact. A cluster analysis identified six modes of co-production: (1) researching solutions; (2) empowering voices; (3) brokering power; (4) reframing power; (5) navigating differences and (6) reframing agency. No mode is ideal; each holds unique potential to achieve particular outcomes, but also poses unique challenges and risks. Our analysis provides a heuristic tool for researchers and societal actors to critically explore this diversity and effectively navigate trade-offs when co-producing sustainability.

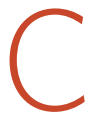
o-production is a rapidly growing endeavour now widely applied in the fields of health, development, education, climate change, industrial production and sustainability ${ }^{1-6}$. It broadly seeks to connect researchers with diverse societal actors to collaboratively and iteratively produce knowledge, action and societal change ${ }^{1}$. The promise is compelling: developing solutions through legitimate processes that draw on diverse and credible expertise with, by and for those best placed to use them ${ }^{5,7,8}$. Sustainability

${ }^{1}$ Forest and Nature Conservation Policy Group, Wageningen University, Wageningen, the Netherlands. ${ }^{2}$ Luc Hoffmann Institute, IUCN Conservation Centre, Gland, Switzerland. ${ }^{3}$ Department of Geography, University of Cambridge, Cambridge, UK. ${ }^{4}$ Institute for Water Futures, Fenner School of Environment \& Society, Australian National University, Canberra, Australian Capital Territory, Australia. ${ }^{5}$ Department of Ecosystem Science and Sustainability, Colorado State University, Fort Collins, CO, USA. ${ }^{6}$ Faculty of Sustainability, Leuphana University of Lüneburg, Lüneburg, Germany. ${ }^{7}$ Institute for the Oceans and Fisheries, University of British Columbia, Vancouver, British Columbia, Canada. ${ }^{8}$ The Peopled Seas Initiative, Vancouver, British Columbia, Canada. ${ }^{9}$ Australian National Centre for the Public Awareness of Science, Australian National University, Australian Capital Territory, Australia. ${ }^{10}$ Centre for Marine Socioecology, University of Tasmania, Hobart, Tasmania, Australia. "Department of Forest and Rangeland Stewardship, Colorado State University, Fort Collins, CO, USA. ${ }^{12}$ Department of Anthropology and Geography, Colorado State University, Fort Collins, CO, USA. ${ }^{13}$ Program in Environmental Design, University of Colorado Boulder, Fort Collins, CO, USA. ${ }^{14}$ Department of Physical and Environmental Sciences, University of Toronto, Toronto, Ontario, Canada. ${ }^{15}$ Stockholm Resilience Centre, Stockholm University, Stockholm, Sweden. ${ }^{16}$ Trinity Centre for Environmental Humanities, School of Histories and Humanities, Trinity College Dublin, Dublin, Ireland. ${ }^{17}$ Department of Environmental Science, Rhodes University, Makhanda, South Africa. ${ }^{18} \mathrm{CSIRO}$ Land and Water, Cairns, Queensland, Australia. ${ }^{19}$ Division of Tropical Environments and Societies, James Cook University, Cairns, Queensland, Australia. ${ }^{20} \mathrm{Fenner} \mathrm{School} \mathrm{of} \mathrm{Environment} \mathrm{and}$ Society, Australian National University, Canberra, Australian Capital Territory, Australia. ${ }^{21}$ Sustainability Research Unit, Nelson Mandela University, George, South Africa. ${ }^{22}$ Earth Observation and Environmental Informatics Group, Wageningen University \& Research, Wageningen, the Netherlands. ${ }^{23}$ The Pew Charitable Trusts, Washington DC, USA. ${ }^{24}$ Department of Natural Resource Science and Bieler School of Environment, McGill University, Montreal, Quebec, Canada. ${ }^{25}$ Architecture, Urban \& Regional Planning, LTD, Hod HaSharon, Israel. ${ }^{26}$ Laboratorio Nacional de Ciencias de la Sostenibilidad, Instituto de Ecología, Universidad Nacional Autónoma de México, Mexico City, Mexico. ${ }^{27}$ School of Geography, University of Leeds, Leeds, UK. ${ }^{28}$ Department of Biology, Chulalongkorn University, Bangkok, Thailand. ${ }^{29}$ Instituto de Ciencias Ambientales y Evolutivas, Universidad Austral de Chile, Valdivia, Chile. ${ }^{30}$ Instituto de Ecología y Biodiversidad, Santiago, Chile. ${ }^{31}$ School of Nature Sciences, Bangor University, Bangor, UK. ${ }^{32}$ University of Jos, Jos, Nigeria. ${ }^{33}$ Institute of Geography \& Center for Regional Economic Development (CRED), University of Bern, Bern, Switzerland. ${ }^{34}$ Stockholm Environment Institute York, Department of Environment and Geography, University of York, York, UK. ${ }^{35}$ Institute of Social Anthropology, University of Bern, Bern, Switzerland. ${ }^{36}$ Hungarian Department of Biology and Ecology, Babeș-Bolyai University, Cluj-Napoca, Romania. ${ }^{37}$ World Agroforestry (ICRAF), Bogor, Indonesia. ${ }^{38}$ School of Geography and the Environment, University of Oxford, Oxford, UK. ${ }^{39}$ Colorado Natural Heritage Program, Fort Collins, CO, USA. ${ }^{0}$ Leiden University, Leiden, the Netherlands. ${ }^{41}$ Stellenbosch University, Stellenbosch, South Africa. ${ }^{42}$ UPEM LISIS INRA, Champs sur Marne, France. ${ }^{43}$ Centre for Development and Environment, University of Bern, Bern, Switzerland. ${ }^{44}$ Department of Human Dimensions of Natural Resources, Colorado State University, Fort Collins, CO, USA. ${ }^{45}$ WWF International, Gland, Switzerland. ${ }^{46}$ Graduate Degree Program in Ecology, Colorado State University, Fort Collins, CO, USA. $凶_{e}$-mail: jmichambers@gmail.com 
is one important arena in which co-production has been increasingly practiced and examined ${ }^{1,5,9}$. Yet, both the meaning and outcomes of co-production remain ambiguous, as efforts now employ diverse terminologies (for example, collaborative governance $^{10}$, social learning ${ }^{4,11}$, co-design ${ }^{12}$, transdisciplinarity ${ }^{13-15}$ and participatory action research ${ }^{13}$ ) linked to varied approaches with different goals, theories, practices, capacities and outcomes ${ }^{1,4,13,16-20}$. Poor conceptual clarity of distinct approaches and the lack of systematic empirical analysis of their outcomes risks framing co-production as a panacea ${ }^{1,7,9}$. Amidst growing concerns over how co-production efforts may in some cases entrench social inequalities and power relations $s^{7,17,21,22}$ or fail to achieve sustainability goals ${ }^{1,13,15,23,24}$, scholarship points to the importance of exploring multiple impact pathways, trade-offs among approaches and cross-scalar dynamics ${ }^{13,23,25}$. Yet, much empirical guidance so far has been limited by scope, often including relatively few case studies ${ }^{15,18,26}$, geographical contexts ${ }^{25,27}$ or methodological approaches ${ }^{28,29}$.

The empirically based analysis presented here of selected examples of co-production provides a heuristic tool for researchers and societal actors to understand the growing diversity of approaches and effectively navigate associated trade-offs when designing co-production processes. Our selected examples focus on one domain of co-production scholarship and practice in sustainability: reshaping how ecosystems can be managed for sustainability. To explore diverse co-production approaches in this domain, we analysed 32 cases that sought to advance sustainable development by co-producing sustainable interactions between people and terrestrial or marine ecosystems (hereafter, 'sustainable development of ecosystems' or, in short, 'sustainability'). We conducted qualitative and quantitative analyses to identify distinct choices in the design and implementation of co-production cases and connect these choices to potential outcomes, challenges and risks. We employed an information-oriented, maximum variation approach to sampling ${ }^{30}$, with 32 cases selected to maximize diversity for sectoral involvement, researcher roles, co-production practices and geographi$\mathrm{cal} / \mathrm{scalar}$ locations. These cases span six continents and operate across local, regional, national, transnational and global scales (Fig. 1). They interweave knowledge and action through diverse methods that combine both descriptive and normative aspects of co-production ${ }^{1,4}$; for example, research-informed co-management processes $^{31-33}$, (trans)national learning networks ${ }^{34,35}$ and global dia$\operatorname{logues}^{36,37}$. All cases sought to beneficially influence how ecosystems function towards sustainability; yet, aspirations ranged from more modest goals of mainstreaming knowledge within established policies to intentions to fundamentally reshape narratives, practices, policies and institutions.

Our analysis emerged from a desire to examine the choices we knowingly or unknowingly make when studying and participating in co-production efforts for the sustainable development of ecosystems, both in the aims that are set and the design choices and practices that shape resulting outcomes. The iterative analyses identified six modes of co-production defined by how they frame the purpose of co-production, conceptualize power, approach politics and theorize impact pathways. Below we describe the diversity of cases and then explore these four themes. We then introduce the six modes of co-production and their unique potential to produce particular outcomes and risks, thereby elucidating when and how particular co-production approaches may be effective and constructive. We conclude by highlighting some critical trade-offs that arise between different modes of co-production and some common features that enhance likelihood of achieving outcomes. We encourage the use of our analysis, particularly as distilled in our graphical visualizations, as a useful heuristic tool to guide researchers and societal actors towards more reflexive co-production design and practice in pursuit of sustainability. The analysis and heuristic presented here are not intended to serve as a generalizable checklist of 'how to co-produce'; rather, our approach seeks to cultivate flexibility and reflexivity that enable researchers and practitioners to plan as well as improvise what action is required in their situation.

\section{Diversity of co-production cases}

The 32 cases engaged with diverse sustainability issues related to habitat degradation, climate change, wildfire and supply chains. All cases were implemented by and/or extensively researched by the 42 co-authors of this paper (the case selection process is detailed in Methods). Some cases worked either at local or global scales, but the majority spanned multiple scales in locations around the world (Fig. 1). All cases fostered collaboration across at least three sectors, with research, government, non-governmental organisation (NGO) and community actors involved in most cases. Societal actors ranged from business $\mathrm{CEOs}^{36}$ and urban planners ${ }^{38,39}$ to indigenous leaders ${ }^{37,40}$ and artists $^{32}$. The cases employed diverse approaches to co-producing knowledge and action, such as participatory modelling to inform resource management ${ }^{33,41}$, research-informed co-management institutions ${ }^{31,38,42,43}$, learning networks or think tanks to guide practice ${ }^{34,37}$, and 'labs' to collectively rethink problems ${ }^{39,44}$. Half the cases engaged people with similar values and goals, while the other half navigated conflicting agendas and, in some cases, bitter disputes.

The combined budget of the cases reached 120 million (median $500,000)$ USD, ranging from short 18-month projects to ongoing initiatives of more than 20 years (Fig. 1). Leadership teams were typically dominated by citizens of project localities, except when working in less developed countries. In addition, two-thirds of all cases were led by at least $50 \%$ women. In some cases, research played a minor role; however, in two-thirds of cases, researchers held relatively greater power over decisions. The majority of cases spanned at least four disciplines such as ecology, social science, art and engineering. Some applied more 'realist' research methods (that is, methods used to describe reality, such as hydrological modelling), while others emphasized 'relativist' methods (that is, methods that study 'reality' as, in part, socially constructed, such as discourse analysis $)^{45}$.

\section{Key differences across co-production cases}

We conducted iterative qualitative analyses to identify key differences in how cases frame and practice co-production and pursue and achieve distinct outcomes. The analyses spanned 2017-2019 and entailed multiple steps (see Methods for details): (1) collaboratively producing a common enquiry framework based on exploratory workshops of co-production cases and literature review; (2) systematically selecting diverse cases; (3) applying the enquiry framework to gather data on each case study in collaboration with a case expert; (4) conducting a preliminary analysis to identify dimensions of difference across cases and then testing and refining a list of 72 dimensions in 2 participatory workshops; (5) systematically assigning numerical scores and qualitative justifications for each dimension of difference for the 32 cases and (6) conducting statistical and qualitative analyses to identify and understand patterns. Four key themes emerged from the analyses: cases varied in their (1) purpose for utilizing co-production, (2) understanding of power, (3) approach to politics and (4) intended impact pathways. For each theme (below), cases typically followed one of two approaches, which can be viewed as opposite ends of a spectrum that sit in tension (Fig. 2). However, some cases demonstrated that these tensions are not inevitable and may be spanned in productive ways.

Purpose. Why do actors co-produce? The motivations driving co-production efforts heavily shape them ${ }^{18,19,46}$. We identified two main motivations underlying co-production: to more effectively solve predefined problems and to reframe problems. Examples of solving predefined problems include initiatives to fill knowledge 
Gaming and simulation for co-learning to mitigate conflict and support collective action in Doi Tiew village, northern Thailand

2007-2010 P.D.

(n)

2013-2019

2011-2014

2016-2019

2017-2018

2016-2019

2013-2018

2013-2018

2011-present J.J.C.

10 Developing climate scenarios and ecological response models to build social-ecological climate resilience in Colorado, USA

11 Building the Durban Research Action Partnership to improve local land-use planning and management around Durban, South Africa

2016-2018

2012-2015

2009-2015

$2013-2019$

15 Reframing 'win-win' conservation and development theory and practice with conservation organizations in northeast Peru

$\bar{\delta} 16$ Alexander River restoration project: restoring a heavily polluted river and fostering cooperation across the Israel-Palestine border

으 17 Chasseral Regional Nature Park: top-down and bottom-up institution building for landscape management in Switzerland

할 18 Improving the uptake of climate models by South Pacific communities and NGOs to build adaptive capacity to climate change

ॠ 19 Future-proofing conservation: enabling adaptive governance in Colombia's protected areas amidst climate uncertainty

20 Enhancing fire-adaptation capacity at multiple scales in the United States through the Fire Adapted Communites Learning Network (FAC-NET)

ণ 21 eWater Cooperative Research Centre: developing a national eco-hydrological modelling and decision support platform in Australia

के 22 Addressing the socio-ecological impacts of conversions to game farming amidst post-apartheid conflicts and power imbalances

๘] 23 Co-producing knowledge and spanning boundaries to promote implementation of freshwater conservation plans in South Africa

을 24 Mongolian rangelands and resilience (MOR2) project: examining pastoral social-ecological systems in rural Mongolia

元 25 SLIM project: analysing and developing social learning processes for integrated water management in 12 sites across Europe

ब 26 Contacted: developing a science-policy-practice framework to reduce environmental risks from production and trade of soy in Cerrado, Brazil

『్ 27 Connecting diverse knowledge systems at multiple scales in IPBES assessments and related science-policy contexts

28 Using science to support community-level and national-level action on conservation and pastoral development issues in East Africa

ક્ 29 Innovating to secure ecosystem services and well-being in telecoupled landscapes in Madagascar, Myanmar and Laos

을 30 Intergovernmental Science-Policy Platform on Biodiversity and Ecosystem Services (IPBES): strengthening science-policy interfaces

त्ञ 31 SeaBOS, emerging from Keystone Dialogues: connecting science with global seafood industry leaders for ocean stewardship

$\frac{\mathrm{O}}{\mathrm{N}} 32$ Developing a global think tank to address the human dimensions of large scale marine protected areas (LSMPAs)

\section{5-present A.B.}

1997-present J.-D.G.

2013-2014 C.C.

2015-2018 C.M. and C.W.

2013-present B.E.G.

2005-2012 M.E.R.

2007-2014 M.S.

2008-2012 J.L.N.

2008-2015 M.E.F.-G.

2001-2004 P.S.

2014-2018 A.P.D., J.M.H.G. and A.M.G.

2011-present M.T.

1999-present R.S.R. and K.A.G.

2015-2020 J.G.Z.

2012-present J.M

2012-present H.Ö.

2014-2017 N.J.B.

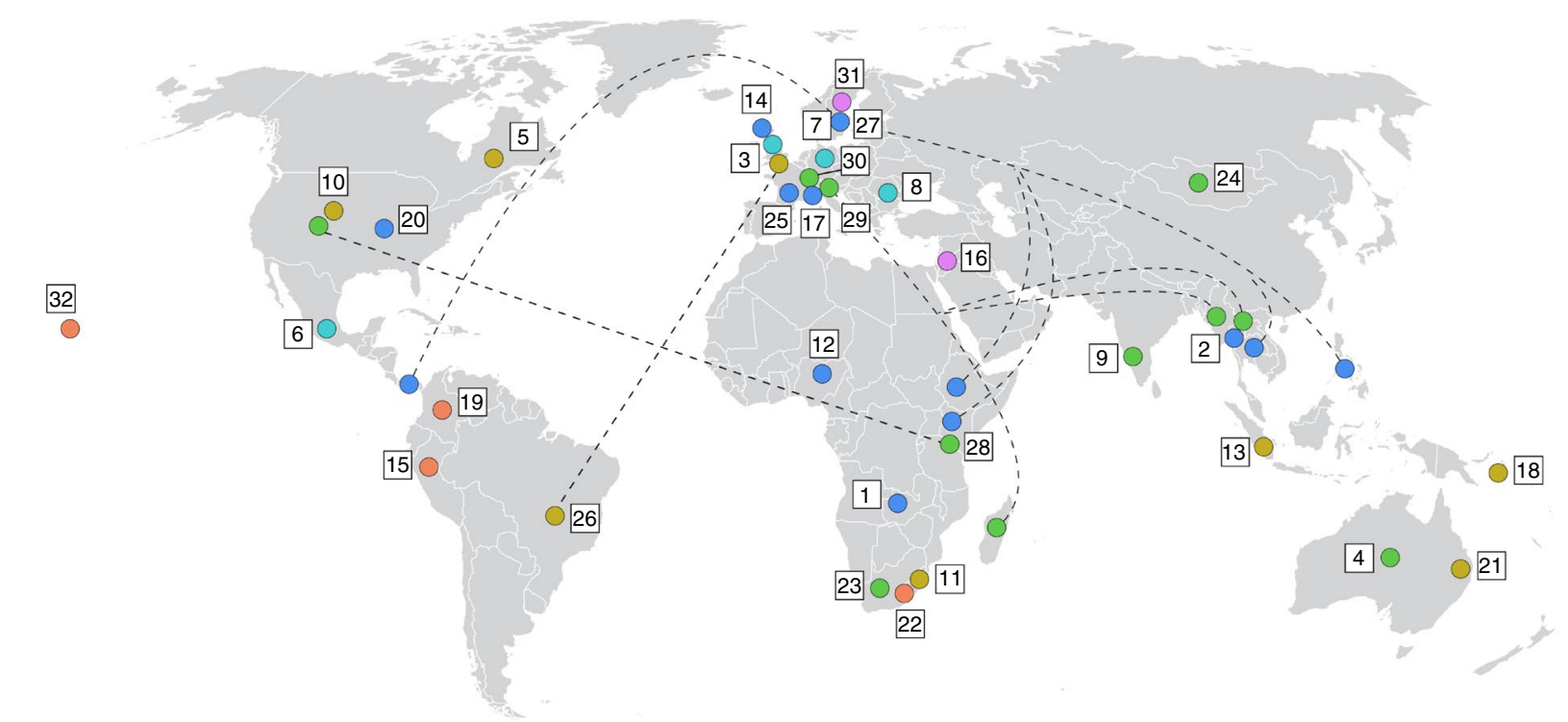

Fig. 1 | Overview of the 32 cases. Cases are grouped by the scale(s) at which the co-production work took place, while the map shows the geographical locations. Dashed lines connect multiple locations that pertain to a single case. Colours indicate the mode identities in Fig. 3. ${ }^{\star}$ Listed contributors provided case materials and interviews, and held a senior leadership position in the case and/or extensively researched it. Additional case details are available in Supplementary Table 1. See Methods for details on the case selection process. Map adapted from webvectormaps under a Creative Commons License CC BY 4.0.

gaps, such as land use impacts on ecosystem services ${ }^{41}$, or collectively manage problems, such as river pollution ${ }^{38}$. Examples of reframing problems include shifting people's focus on ensuring sustainable production of a commodity to becoming an active steward of the ecosystem on which that product depends, whether farmers/fishers in a local resource context $t^{31,33,44}$ or corporate actors with global influence ${ }^{36}$. Earlier problem definition facilitated quicker solutions, but also inhibited participants from questioning their assumptions. For example, partnerships between researchers and policymakers explored more topics over time, but rarely questioned their assumption that a lack of knowledge was the primary barrier to change. Cases seeking to reframe problems engaged actors with divergent views to either negotiate compromise or facilitate reframing. Reframing was sometimes pursued unidirectionally (that is, using knowledge to convince actors), but others created spaces to collectively question multiple perspectives in ways that placed them on equal ground. Projects that emphasized reframing often struggled to engage solutions-oriented actors and produce concrete actions. Cases were therefore often challenged by an apparent paradox: they 


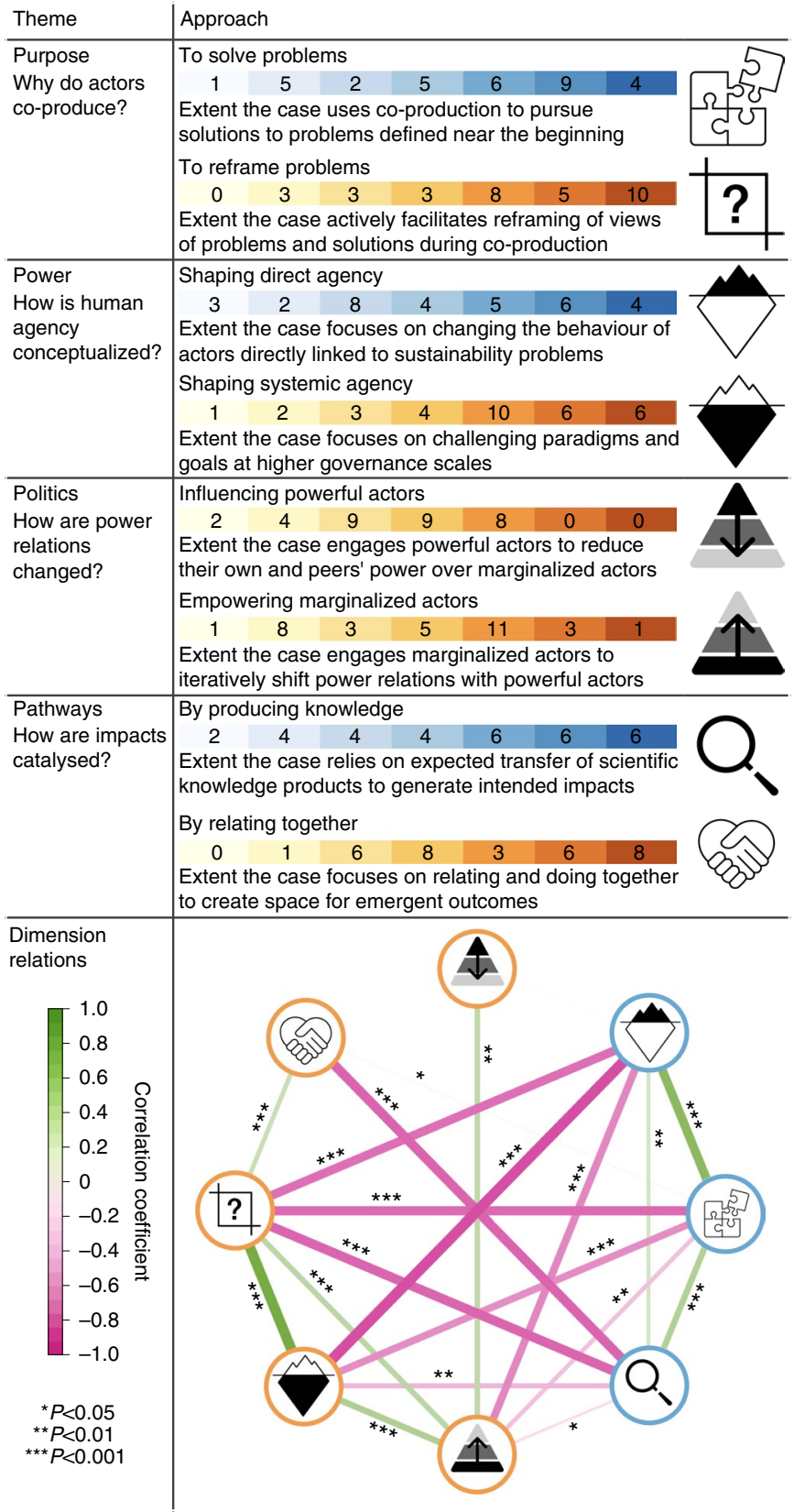

Fig. 2 | Eight key differences in how cases approach co-production. The number of cases that exhibited each approach at varying strengths is shown (lightest shade $=$ no emphasis; darkest shade $=$ very strong emphasis); for example, four cases heavily focused on solving predefined problems, whereas one case did not define any solutions at the start. The correlations diagram shows the key tensions between blue and orange approaches, meaning that cases rarely managed to strongly employ both. The stronger the correlation between two approaches, the wider the connecting line (green, positive; pink, negative). See Methods for the scoring process of these approaches (dimensions) and Supplementary Table 2 for detailed seven-point Likert scale definitions and illustrative quotes. Images adapted from the Noun Project under a Creative Commons License CC BY 3.0: handshake by Chunk Icons, magnifying glass by kiddo, pyramid by IconPai, arrow by Alice Design and iceberg by Juan Pablo Bravo.

needed to stabilize problem framings to align actors and empower action, while also questioning problem framings to spark more diverse and innovative possibilities.
Power. How is human agency conceptualized? Power and agency are inherent to sustainability scholarship, yet these concepts are interpreted in diverse ways ${ }^{47-49}$. We identified two predominant approaches to understanding human agency: focusing on the behaviour of actors directly linked to sustainability problems (for example, encouraging resource users to extract less or recuperate habitats ${ }^{41,50}$ ) versus targeting more systemic aspects (for example, addressing broader paradigms and systems that influence resource users' agency $\left.{ }^{37,51}\right)$. This echoes different definitions of 'power' in the literature, ranging from more direct interactional forms (that is, exercising 'power over' others), to diffuse, structural and preconstituted forms ${ }^{47}$. While the direct approach was typically seen in cases focused on solving problems, the more systemic approach often emerged from processes that used iterative dialogue and creative methods to reframe participants' perceptions of agency ${ }^{32,44}$. Some cases realized contradictions over time between their direct actions (for example, supporting local communities to adapt to climate change) and failure to address systemic issues that constrained those actions (for example, policies and actors causing climate change $)^{40}$. Projects therefore struggled to navigate tensions between promoting a limited view of agency to empower direct action and expanding views to consider systemic issues that could leverage wider impact. While the former risked failing to address the roots of sustainability problems, the latter risked disempowering individual agency if people felt overwhelmed by 'big' systemic challenges.

Politics. How are power relations changed? Co-production literature increasingly explores the politics inherent to reshaping relations of power among actors ${ }^{16,21,52}$. Here we refer to politics as the work of deciding who gets what, when and how, which refers to a broader sphere of engagement than the deliberation of official government processes ${ }^{53}$. We identified two distinct ways that cases engage with politics to reshape power relations: by empowering marginalized actors, such as grassroots groups or local officials, or by influencing powerful actors, such as international policymakers or corporate executives, to yield power. Most cases focused on local actors; for example, by empowering municipal officials through provision of science-based evidence to engage political decision makers ${ }^{54}$. Some sought to persuade actors to change behaviours defined as problematic by actors external to the context (for example, exploitation of natural resources by farmers ${ }^{50}$ ), while others began with local interpretations of problems ${ }^{43}$. Several cases facilitated integration of local and external views to develop new possibilities for action. Some took the further step of representing these views in decision-making arenas or gave local actors a seat in discussions with more powerful actors. Yet, very few cases sought to reshape power relations through deep engagement with globally powerful actors, or directly connected them to iterative bottom-up processes. Indeed, cases that directly engaged powerful actors rarely questioned their control over particular actors. This dynamic played out within some project teams, where actors from the global north held greater control over co-production processes occurring in the global south, with no cases of the reverse ${ }^{55}$. Cases therefore tended either to not actively attempt to influence the politics that shaped power relations or struggled to navigate the politics of shifting power by iteratively engaging one, or occasionally both, sides of power differentials.

Pathways. How are impacts catalysed? Co-production initiatives exhibit diverse possible impact pathways ${ }^{23,56}$. Our cases employed two main pathways: by primarily producing scientific knowledge as a product that is expected to shape policy and/or practice (that is, 'by producing knowledge'; Fig. 2) or through more integrated forms of knowing, relating and doing (that is, 'by relating together'). Examples of producing knowledge included developing new scientific research outputs such as academic journal articles or reports 

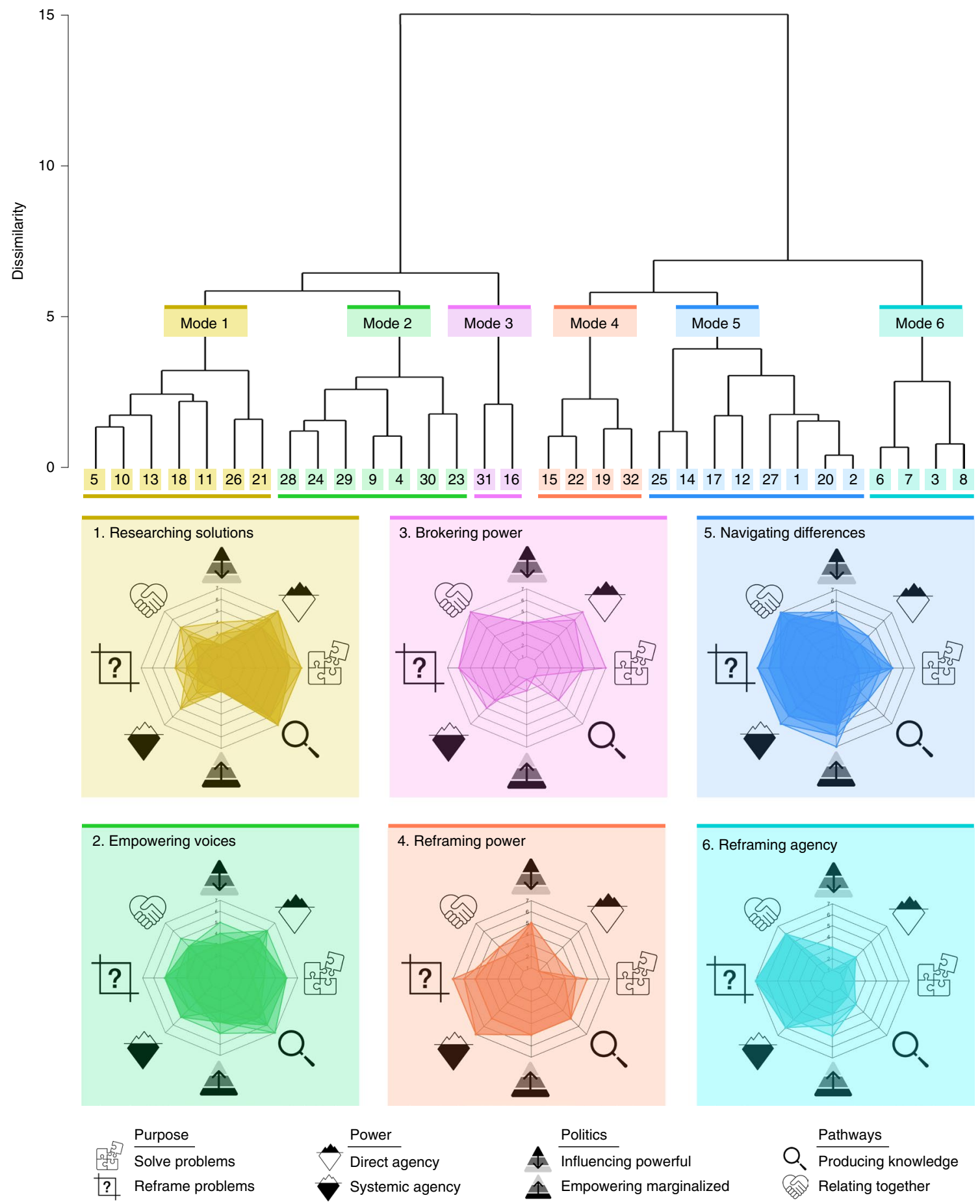

Fig. 3 | Six modes of co-production identified by approaches to purpose, power, politics and pathways. Spider diagrams show the value of each of the eight approaches for all case members of each mode. Case identifiers (IDs) and mode colours correspond to those in Fig. 1, demonstrating the high geographic and scalar diversity within each mode. See Methods for further details on the hierarchical clustering process. Images adapted from the Noun Project under a Creative Commons License CC BY 3.0: handshake by Chunk Icons, magnifying glass by kiddo, pyramid by IconPai, arrow by Alice Design and iceberg by Juan Pablo Bravo.

for policymaking and practice (for example, guidelines for practitioners $)^{54,57}$. Examples of relating together emphasized iterative dialogue to share practical experiences of the actors involved ${ }^{36,37,39,44}$ and direct action through co-managing ecosystems and creating new institutions and policies ${ }^{31,32,34,38}$. Many cases focused on producing knowledge, clearly linked to the dominant role of researchers in our sample of cases. These cases often quickly stabilized notions of problems, such as the need to fill particular knowledge gaps related to interventions, resource/information flows or actors' perceptions. The actors that this knowledge sought to influence were involved in varied ways, from informing questions to co-producing research or engaging in social learning around the produced knowledge. In contrast, cases that focused less on producing scientific knowledge outputs typically emphasized relating together. This latter approach was associated with fewer predefined goals and more space to enact emergent ideas. 


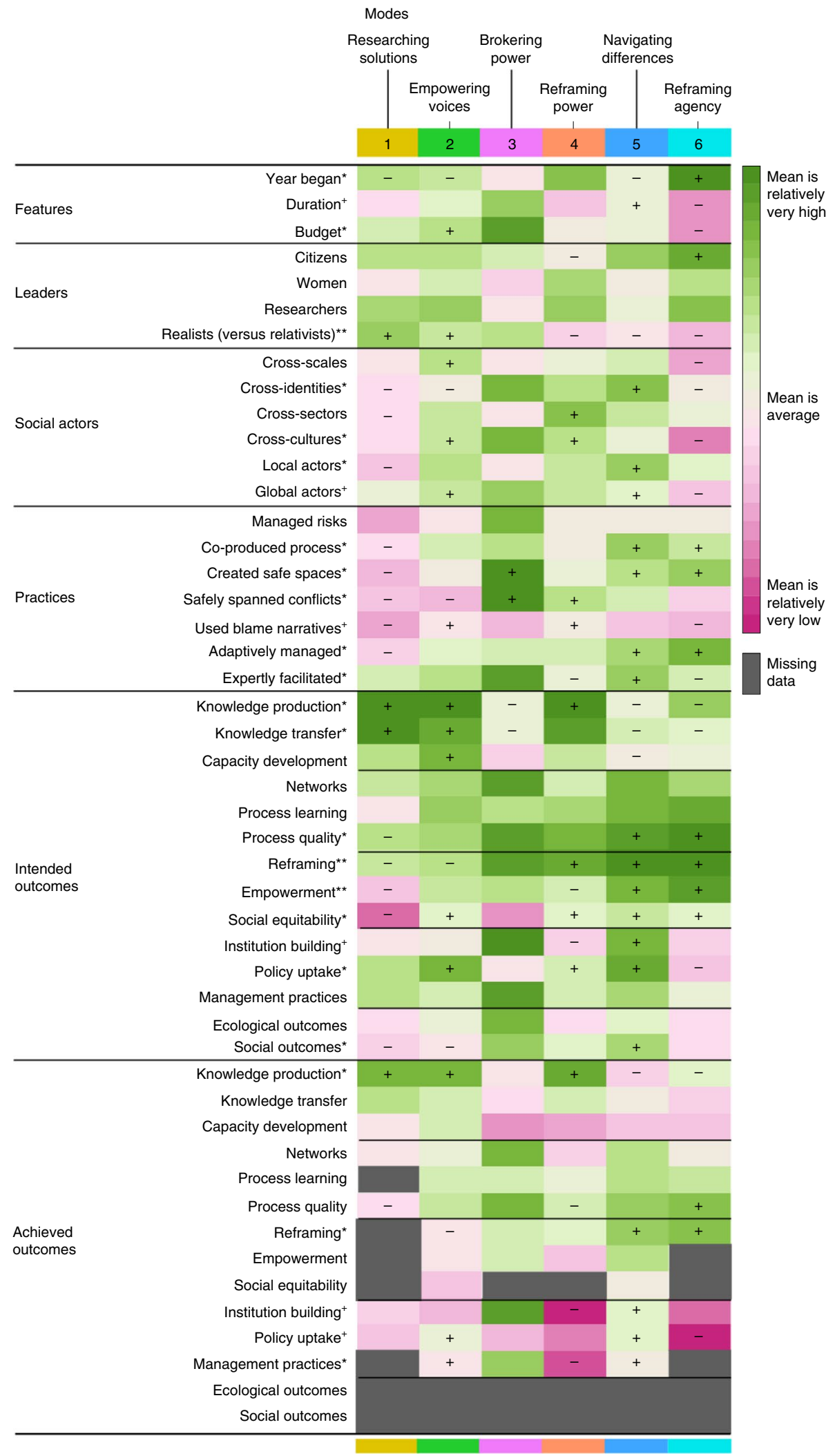

Fig. 4 | Comparison of co-production modes by main features and outcomes. The + /- symbols indicate which mode means are significantly higher/ lower for each dimension, with the overall significance of comparisons denoted (Kruskal-Wallis tests; ${ }^{+} P<0.10,{ }^{\star} P<0.05,{ }^{\star \star} P<0.01,{ }^{\star \star \star} P<0.001$ ). For example, modes 1, 2 and 4 achieved more knowledge production, whereas modes 5 and 6 achieved more reframing. Mode 3 rarely exhibited statistically significant differences due to its small size. Outcomes are grouped into intercorrelated sets (Fig. 6). Results are greyed out when missing $>50 \%$ of data for modes with 7-8 cases and $>25 \%$ of data for modes with 2-4 cases. Descriptive dimensions that did not exhibit notable differences are not shown. See Supplementary Tables 3 and 4 for definitions of all descriptive and outcome dimensions, respectively, and Supplementary Fig. 1 for correlations among all descriptive dimensions. 


\section{Modes of co-production}

The hierarchical clustering ${ }^{58}$ analysis grouped cases that similarly approached purpose, power, politics and pathways into six clusters (Fig. 3). Clusters represent distinct modes of co-production that employed particular designs and practices to pursue up to 14 types of identified outcomes. These modes varied in their aims (Fig. 4); for example, some particularly sought to produce scientific knowledge outputs (1,2 and 4), reframe pre-existing beliefs and values (2-6), enhance policy uptake $(1,2,4$ and 5) or build institutions (3 and 5). For each mode, we discuss their main features and key strengths and weaknesses in relation to the extent that cases pursued and achieved particular outcomes (Fig. 4). We connect this discussion to the unique opportunities and critical risks associated with different approaches to navigating purpose, power, politics and pathways (Fig. 5).

Mode 1. Researching solutions. Here scientists and decision makers employing more 'realist' investigative methods ${ }^{45}$ such as ecosystem modelling produced practical scientific knowledge with the goal to influence policies and interventions. Cases varied in the relative power of scientists or decision makers to define topics but spanned relatively low social diversity of actors. These projects generated evidence that could inform or justify the approach of environmentally motivated decision makers. This was most effective within institutional contexts that supported actors to iteratively evolve relationships, questions and methods over time and to adapt to shifting policy contexts ${ }^{54}$. However, this approach was less effective at shifting the strategies and priorities of decision makers, who were more receptive to knowledge that helped rather than opposed their plans. The emphasis of these projects on lack of knowledge as the principal barrier to change therefore often limited their capacity to realize broader recommended shifts in management and policy. Cases also struggled to support emergent goals, such as addressing capacity needs. Efforts to empower scientific knowledge risked marginalizing the voices of other actors (and knowledge systems) who were excluded from the process but affected by resulting recommendations ${ }^{21}$.

Mode 2. Empowering voices. These cases also co-produced knowledge to address ecosystem management and policy challenges, led by interdisciplinary scientists alongside community and/or government actors. However, they differ from mode 1 through their explicit intention to empower relatively marginalized actors and include greater social diversity, such as by supporting initiatives of local and indigenous communities. Cases created meaningful solutions for local actors and produced science to confront broader narratives that furthered ecosystem degradation and social inequalities $^{43,59}$. Several cases navigated a careful balance between neither suppressing nor romanticizing local views by developing respectful ways to integrate external expertise and expand problem definitions ${ }^{40,43}$. Compared with mode 1 , cases emphasized process and more actively engaged with/in policy and management contexts, producing greater impacts ${ }^{57}$. Outcomes were enhanced for cases that prioritized process learning and quality, fulfilled capacity needs and built institutions to evolve multi-scalar partnerships and activities over time. However, the strong emphasis on producing and empowering particular knowledge forms constrained possibilities for reframing. This knowledge could also be ignored by higher level decision makers who were often not deeply involved, hindering initiatives' broader desired social equitability outcomes.

Mode 3. Brokering power. This mode was the smallest and was highly unique. Both cases engaged relatively powerful actors to develop long-term innovative institutions to address sustainability challenges. In contrast to modes 1 and 2, these cases fostered dialogue around synthesized knowledge and took direct policy and management actions, instead of mainly producing scientific knowledge. Both cases also equally focused on reframing problems and pursuing solutions, yet did so in distinct ways. One case created a safe space for international CEOs and scientists to reframe views of ocean sustainability problems to develop governance solutions ${ }^{36}$. The other case took collective action to restore a polluted river, using a shared concern as a pathway to build trust and reframe polarized relations in a cross-border conflict ${ }^{38}$. These cases used third party brokers and carefully controlled participation to facilitate safe spaces for dialogue, given the high potential for conflicts among identities and interests. Tracking process results was critical to fostering ongoing engagement and navigating a balance between speaking the language of powerful actors while trying to reframe thinking. Due to the stronger emphasis on scientific/technical expertise (over local knowledge and concerns), these cases risked legitimizing existing power relations.

Mode 4. Reframing power. These cases engaged both relatively marginalized and powerful actors (for example, local communities and national NGO and government actors) to reframe technocratic narratives and shift practices and policies that marginalize social concerns $^{37,51,60}$. Like in mode 3 , they were led by researchers alongside relatively powerful practitioners. However, in contrast, researchers explicitly sought to shift power away from powerful actors and towards marginalized actors whose perspectives they explored using 'relativist' critical social science methods. As a result, some reframing of dominant perspectives occurred; however, cases struggled to create 'safe enough spaces' ${ }^{29}$ to do so. This was partly due to spanning multiple cultures, sectors and identities during relatively short timelines $^{37}$ and partly related to their emphasis on producing knowledge (like modes 1 and 2) and little focus on institution building (unlike mode 3). This shifted the balance of power towards researchers, who faced the challenge of keeping work critical of power relations, while also trying to relinquish power to solutions-oriented actors to foster practical relevance ${ }^{51,60}$. Only cases with strong existing institutional roots or multi-scalar networks managed to somewhat shift policy and practice ${ }^{37,60}$.

Mode 5. Navigating differences. This mode is distinguished from modes $1-4$ by a stronger emphasis on managing processes of relating together, learning and empowerment over producing and transferring scientific knowledge about human-ecosystem interactions. Researchers employed more 'relativist' methods ${ }^{45}$ but, in contrast to mode 4, they held less power. Facilitation techniques and boundary objects ${ }^{61}$ were used to connect stakeholder groups to explore conflicts and reframe perspectives, while allowing new institutions, regulations and practices to emerge. These processes valued all forms of expertise, and effectively minimized hierarchies to directly engage with actors across power differentials ${ }^{31}$. This model showed promising evidence of reframing, for example, by changing fixed notions of 'stakes' to more dynamic 'stakeholding ${ }^{34}$ and shifting scientific knowledge from a dominant position to a more democratic one $^{32}$. The early focus on reframing (instead of generating solutions) allowed actors to navigate conflicting identities to build long-term (mean of eight years), complementary bottom-up and top-down processes $^{32,42}$. This resulted in higher attainment of policy and management outcomes. Some cases additionally linked diverse local co-production efforts through learning networks ${ }^{34,35}$. A few cases were blocked by unsupportive high-level actors, underscoring the importance of managing those risks and building trust across power differentials.

Mode 6. Reframing agency. These cases focused the least on using co-production to solve predefined problems. Led mostly by researchers with both highly relativist design and systems thinking backgrounds, they created safe spaces to identify collective 


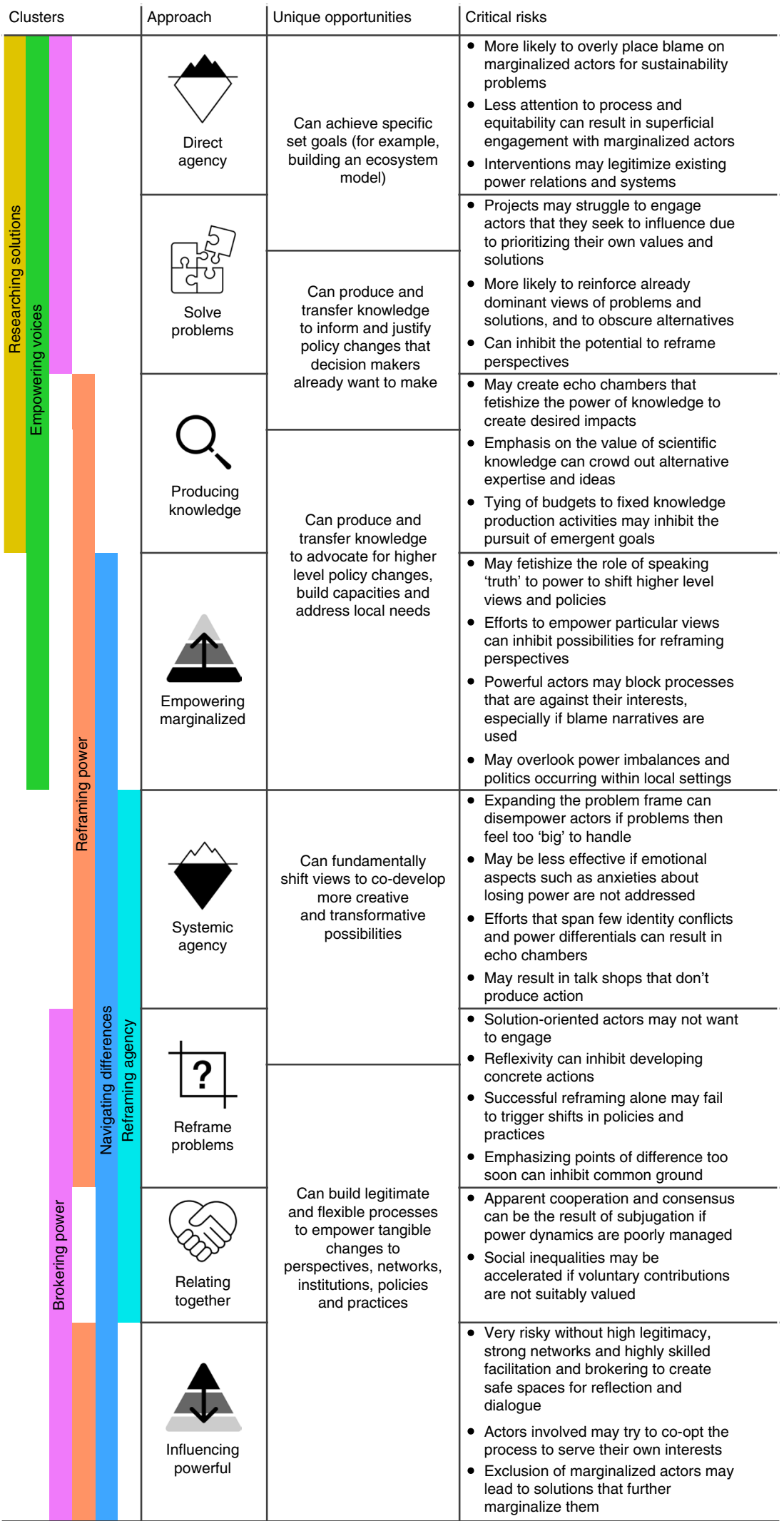

Fig. $\mathbf{5}$ | The unique opportunities and critical risks of different modes of co-production. When co-production initiatives strongly express particular combinations of approaches to purpose, power, policies and pathways, they hold unique ability to achieve certain outcomes, but each approach is also linked to critical risks. For example, modes 1 (researching solutions) and 6 (reframing agency) face the opposite opportunities and risks. The ability of modes 3 and 5 to achieve multiple types of outcomes (Fig. 4; for example, reframing, networks, management practices and institution building) is related to their unique ability to span the dichotomies: purpose (problem solving and problem reframing) and politics (influence powerful and empower marginalized), respectively. In contrast, modes 1 and 6 achieved fewer types of outcomes (Fig. 4). Images adapted from the Noun Project under a Creative Commons License CC BY 3.0: handshake by Chunk Icons, magnifying glass by kiddo, pyramid by IconPai, arrow by Alice Design and iceberg by Juan Pablo Bravo. 


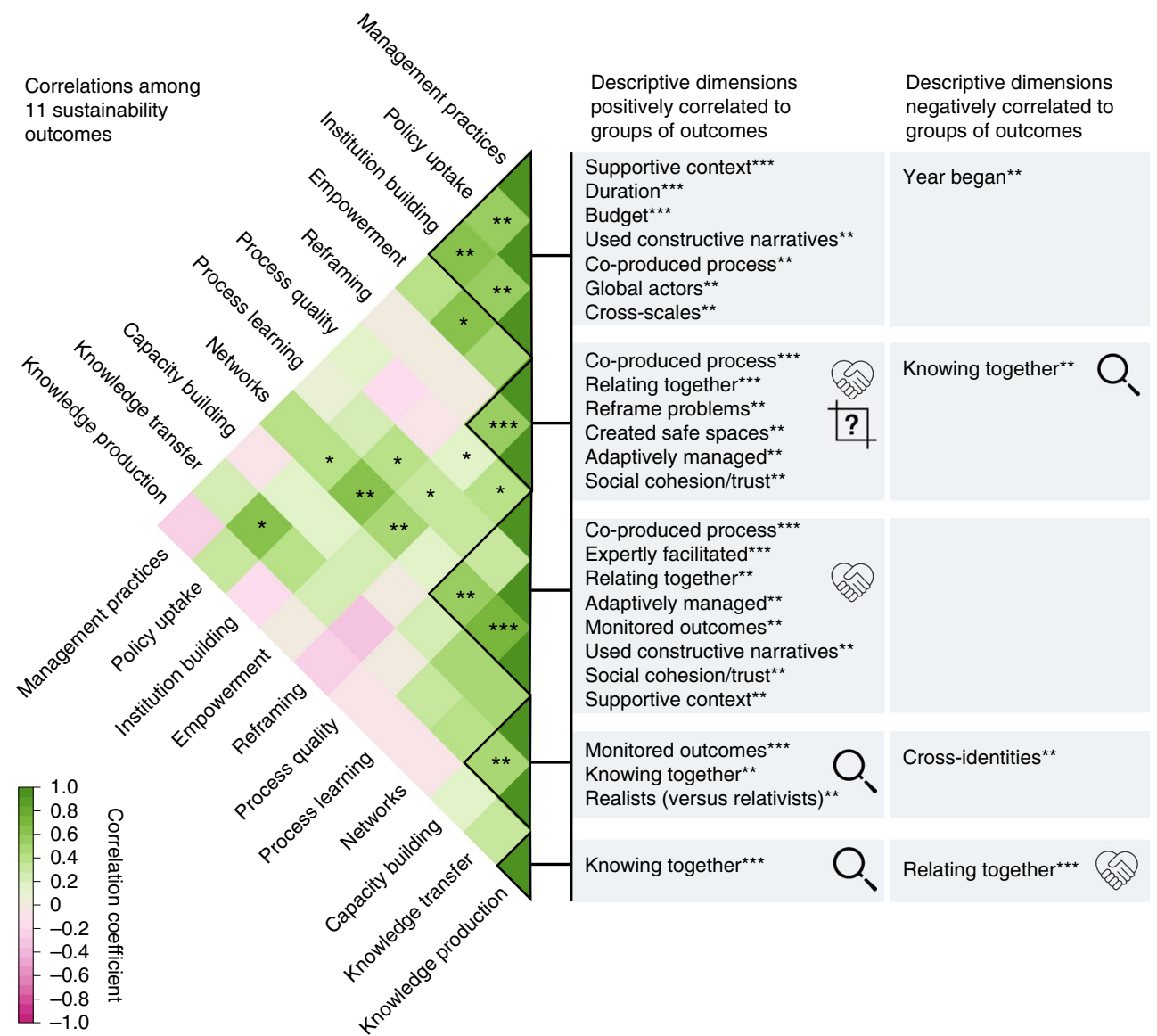

Dimensions significantly linked to higher attainment of outcomes across the board
1. Highly collaboratively designed and practiced process (co-produced process ${ }^{\star \star \star}$ )
2. Very effective facilitation across social-political differences (expertly facilitated ${ }^{\star \star \star}$ )
3. Very supportive funding arrangement and broader context (supportive context $^{\star \star \star}$ )
4. Extensive effort to monitor process and results-oriented outcomes (monitored outcomes out $^{\star \star \star}$ )
5. Strong levels of social cohesion and trust reached among actors (social cohesion/trust ${ }^{\star \star \star}$ )
6. Use of narratives that frame issues constructively (use constructive narratives ${ }^{\star \star}$ )
7. Engagement with actors that work at higher scales during the process $\left(\right.$ global actors $^{\star \star}$ )
8. Collaborative processes that continue to engage over long periods (duration ${ }^{\star}$ )
9. Processes that connect work across local/regional and national/global scales $\left(\right.$ cross-scales $^{\star}$ )

Fig. 6 | Dimensions most strongly associated with higher attainment of sustainability outcomes. The green/pink grid shows how achieving some outcomes is positively/negatively linked to achieving other outcomes $\left({ }^{\star} P<0.05,{ }^{\star \star} P<0.01,{ }^{\star \star \star} P<0.001\right)$. Knowledge production is the only outcome that is not correlated with achieving any other outcomes, and even shows a consistent negative trend. The descriptive dimensions that are most strongly correlated with each subgroup of intercorrelated outcomes are listed in the grey boxes. The white box contains all dimensions that are significantly linked to higher attainment of outcomes across the board. The definitions for all descriptive and outcome dimensions, and common methods that cases used to assess them, are available in Supplementary Tables 3 and 4, respectively. Images adapted from the Noun Project under a Creative Commons License CC BY 3.0: handshake by Chunk Icons and magnifying glass by kiddo.

forms of agency capable of addressing systemic governance issues, such as through urban/transformation labs ${ }^{39,44}$. These cases did not seek to empower particular knowledge, but instead allowed diverse knowledge forms to be expressed. To create safe spaces, they engaged environmentally motivated change agents in local contexts, thereby spanning fewer conflicting identities and cultures. They also explored emotional and psychological anxieties related to questioning power and beliefs ${ }^{39}$. Despite their relatively short duration, these cases most effectively triggered reframing, illustrating the value of creating spaces without explicit solution agendas. For example, in one case participants realized an incongruence between their own narratives and practices, leading them to shift focus from agro-technologies to fostering social solidarity ${ }^{44}$. These cases also trained participants to employ co-production approaches in their own work. Few shifts in policy and practice have been documented; however, these projects did not explicitly seek these outcomes and were among the most recently completed. These cases struggled most to engage powerful impact-motivated actors and risked creating echo chambers (that is, spaces where people encounter views that mainly coincide with their own).

\section{The outcomes and future of co-production for sustainability}

This analysis unpacks the diverse design and implementation choices that fall within the growing field of co-production scholarship and practice for the sustainable development of ecosystems. 
The six co-production modes we identify show how distinct approaches to engaging with purpose, power, politics and pathways are suited to achieving different types of outcomes. Yet, approaches also differ in their potential risks, such as creating echo chambers, reinforcing the status quo and being co-opted by powerful vested interests (Fig. 5). By clarifying the connections between co-production choices and differential benefits and risks, we provide a heuristic tool to enhance understanding and design considerations where researchers and societal actors interweave knowledge and action for sustainability. For example, among our cases, design choices that prioritized relating together and systemic interpretations of agency were crucial to reframing perspectives, while knowledge-focused and solution-oriented approaches were better suited to influencing policy. Particular approaches may also be appropriate in different stages of a change process, and further research may explore the role of certain approaches in varying contexts $^{62}$. We therefore argue that this diversity is a strength: different approaches contribute to change in distinct ways if the associated risks are proactively managed (Fig. 5).

In accordance with other studies ${ }^{13,16,63}$, our analysis shows that co-production requires careful facilitation to bridge diverse perspectives, values and identities, and that multi-scalar and long-term engagement is essential for achieving outcomes (Fig. 6). Our cases collectively highlight just how varied the possible outcomes of co-production are, from informed policies and shifted narratives to reshaped relations and institutions. Yet, particular synergies and trade-offs emerged among these outcomes (Fig. 6). For example, cases that fostered the most substantial reframing of perspectives and feelings of empowerment (for example, in reframing agency) did not demonstrate shifts in policies or practices. Another notable trade-off is that the successful production of scientific knowledge was consistently negatively associated with attaining most other outcomes (Fig. 6). Similar to recent studies ${ }^{13,15,64,65}$, our analysis suggests that the tendency of researchers to direct co-production resources to filling knowledge gaps, whether led by natural scientists (for example, in researching solutions) or critical social scientists (for example, in reframing power) - may actually hinder the attainment of other types of outcomes that inspire collective action, such as reframing narratives and building institutions.

Our study suggests that co-produced scientific knowledge can further existing policy goals; however, when the goal is to fundamentally reframe policies, we found that cultivating dialogue and relations that question problem definitions and explore systemic forms of agency are critical (for example, navigating differences and reframing agency; Fig. 4). Co-production efforts that demonstrated the largest shifts in institutions and management practices directly supported researchers and diverse societal actors to iteratively balance critically reflexive and solutions-oriented spaces (for example, brokering power and navigating differences; Fig. 4). This allowed actors to navigate different agendas for change to grow ideas and actions which were unforeseen from the outset. While several local cases spanned these dual reflexive and action-oriented purposes of co-production, we call for greater exploration of how to do so across scales, and in particular with globally powerful actors.

Despite the promising outcomes of diverse co-production practices, their ultimate sustainability impacts remain unclear since few cases monitored social (13\%) and ecological (22\%) aspects of sustainability, such as improved human well-being amidst more sustainable resource levels. Attributing such impacts to co-production processes is challenged by their often spatially and temporally dispersed and unanticipated effects. We therefore support others' calls for approaches that iteratively monitor impacts occurring within (and not just after) co-production processes to support adaptive learning while acknowledging complex and unpredictable impact

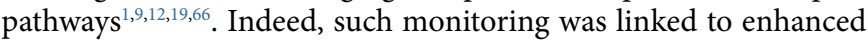
achievement of outcomes across our cases (Fig. 6). For example, one case examined people's cognitive maps, perception of agency and social networks at multiple stages during the process to facilitate and document the changes occurring ${ }^{44}$ (see Supplementary Table 4 for more approaches). We therefore echo existing concerns that funding paradigms and policy orientations requiring predefined problem definitions and impact pathways may constrain the full range of possible outcomes of co-production ${ }^{5,66}$.

Undertaking this analysis enabled us to collectively and critically interrogate the diverse assumptions behind the purpose of our co-production practices, ways of navigating power and politics and presumed pathways to sustainability. We have produced a heuristic that can be used to support researchers and practitioners to navigate the trade-offs and risks associated with different approaches to weaving knowledge, action and change. Given similar co-production challenges around power, impact and scale experienced across diverse fields ${ }^{1,4,13,21,63}$, this tool may help facilitate critical reflection in other contexts or otherwise inform the design of additional analyses that go even further in depth and wider in scope. We encourage the application of our heuristic as a reflexive tool to open dialogue and strengthen transparency in design choices in co-production processes for sustainability, and welcome future evaluations of its effectiveness for guiding scholarship and practice.

\section{Methods}

This study was collaboratively produced by contributors of the 32 cases through an iterative exploratory and analytical process during 2017-2019. We took a dialogical approach ${ }^{67}$ in the overall study design by deliberately iterating between analysis conducted by the lead author (J.M.C.) and interrogation of those analyses by case contributors over multiple stages (further described below). This allowed the lead author to maintain independence of interpretation by individually conducting all interviews and empirical analyses, while conceptual framings and analytical interpretations of the study were iteratively improved by the in-depth practical knowledge of the diverse range of co-production experts involved. Workshops were organized at two different stages of the analysis to also foster an interactive space to co-develop the focus, scope and methods for the analysis (further described below). This iterative, multi-stage analysis resulted in a highly robust methodological approach to advance collective knowledge around diverse co-production framings, approaches and outcomes. Our choice to collaboratively produce this research is consistent with a growing number of scholars who underscore the importance of researchers producing knowledge with those who are actually implementing the work under study to produce rigorous knowledge of important practical experiences $^{26,68}$.

Collaboratively produced common enquiry framework. The research began with two participatory workshops, one convened at The Pew Charitable Trusts in Washington D.C., USA (23-25 May 2017) and the other at the 2nd Programme on Ecosystem Change and Society (PECS) Conference in Oaxaca, Mexico (11-12 November 2017). A number of scholars and practitioners working on different aspects of 'co-production' were invited to the Pew workshop, while participants self-selected into the PECS workshop, based on their interest and prior experience working on co-production. In these workshops, we grounded our analysis in the experience of the co-production cases. Case contributors responded to a series of open questions regarding co-production aims, practices and outcomes, followed by participatory exercises to identify key differences and common challenges. The 25 participants in these workshops collectively represented more than 200 years of cumulative practical experience managing co-production initiatives for the sustainable development of ecosystems in 15 countries. Participants were diverse in terms of career stage, disciplinary background and position, with half based in research institutes and nearly all in positions operating at the interface of research and policy/practice (that is, 'scholar practitioners'). However, participants were predominantly women $(80 \%)$ living in the global north $(85 \%)$, which undoubtedly shaped the discussions in the workshops. In an effort to rectify these biases, we subsequently conducted a wider review of relevant co-production literature to further develop the emerging common enquiry framework (that is, a spreadsheet to enquire about important differences across diverse co-production cases) to guide subsequent data collection and analyses.

Systematic case selection. The 32 cases included some from the initial workshops $(n=8)$ and others subsequently identified using Google Scholar $(n=24)$. Our sampling approach followed an information-oriented, maximum variation approach to sampling: we selected cases that would give the greatest possible information about co-production for the sustainable development of ecosystems, a subgroup in the domain of co-production for sustainability ${ }^{30}$. This selection strategy provided analytical power for exploring how different co-production aims, 
features, practices and outcomes are interlinked. To select a broad range of cases, we chose to maximize diversity for sectoral involvement, the role of researchers, co-production practices and geographical/scalar locations. While our sample has proven effective for identifying patterns, including the six modes of co-production, it has inherent limitations for attempting hypothetico-deduction. For example, we cannot determine which of these modes is more prevalent across the whole population of co-production for the sustainable development of ecosystems, or sustainability more broadly; nor can we draw general conclusions about the causeeffect linkages between modes and outcomes. A larger stratified random sample would be more effective for such purposes.

The eight cases selected from the workshops had been running for longer than two years and employed different co-production approaches to address challenges related to the sustainable development of ecosystems. The Google Scholar searches individually paired 10 ecosystem-focused variants of the term 'sustainability' such as 'social-ecological', 'ecosystem services' and 'marine conservation' with 22 variants of 'co-production' such as 'co-design', 'co-management', 'social learning', 'action research' and 'transdisciplinary' (see Supplementary Table 5 for a complete list of search terms). The co-production terms were selected by identifying key terminologies that appeared in co-production literature $e^{1,13,14,16}$. The range of sustainability and co-production terms ensured that our selection of co-production initiatives encompassed the diversity of approaches and contexts we found in the literature. Since we used Google Scholar to expand the diversity of our initial set of cases, our sample is biased towards co-production cases published in international peer-reviewed journals, as this work is more likely to be well known and highly cited. We set a clear 'co-production' boundary for our set of cases by excluding cases that were captured by our search terms but were not interweaving knowledge, action and change. For example, collaborative governance interventions were only included in this study if they interweaved knowledge, action and change among participants; this meant excluding NGO- or state-led participatory interventions that did not involve researchers.

Despite the leading role of researchers in many cases, we sought to gather cases that spanned diverse research roles, from practitioners conducting knowledge synthesis to researchers generating knowledge or facilitating dialogue. It was also difficult to engage local projects led by non-English speakers who do not have international networks. We therefore actively sought to include cases from a diverse range of contexts, with multiple cases in each broad geographical region, to incorporate some degree of cultural diversity. We acknowledge, however, that we first prioritized diversity in terms of co-production approaches, and only one-fifth of our sample is both located in the global south and led by citizens of those countries. We therefore underscore the need for further work to examine approaches to co-production led by citizens of the global south. Only three potential case contributors that we contacted declined to be involved in the project.

Data collection. Applying the common enquiry framework developed in the initial stage of the research, we collected the following qualitative data for each case: (1) how co-production and sustainability challenges are framed, (2) how co-production is designed and implemented in practice, (3) the rationales underpinning decisions on how to co-produce, (4) capacities which support or hinder co-production and (5) outcomes of co-production. The lead author completed a qualitative spreadsheet in partnership with a key representative of each case. For 29 cases, this was a senior leader in the co-production process, while for 3 cases, this was someone who had extensively researched the case. The lead author interviewed most case representatives for approximately an hour to gather further qualitative information related to written responses in the spreadsheet. In a few cases, this was not necessary, as we gained sufficient case detail through email correspondence. To understand a broader range of perspectives of people involved in each project, we also reviewed a mean of 6 documents and publications per case (186 total), reviewing a greater number if the case was not yet published in peer-reviewed literature. The lead author worked individually with each case contributor (an expert in the particular co-production process) to gather relevant and reliable materials to inform interpretations of the case, which spanned a mixture of scientific articles, grey literature and internal documents. To ensure a robust assessment of outcomes across different forms of evidence, the lead author scored the quality of the evidence for each reported outcome by each case and consulted with the case contributor to ensure further evidence was unavailable. The 22 missing data squares in Fig. 4 reflect the exercised judgement of the lead author that the quality of evidence was insufficient to substantiate claims regarding those outcomes. Given the sensitive nature of reporting outcomes and case difficulties, to enhance open exchange and accurate reporting, case contributors were given the opportunity to indicate any parts of the data gathered about their project that they wish to remain anonymous in any outputs related to this project.

Preliminary analysis and testing of dimensions of difference. The lead author conducted a preliminary analysis by qualitatively coding each of the five aforementioned categories of data using NVivo Software, grounded in the data from and understanding about each case from the case contributors ${ }^{6}{ }^{9}$. Two rounds of coding of the common enquiry spreadsheets (completed for each case) and additional case documents and interviews led to the identification of numerous qualitatively described dimensions of difference across all cases.
These dimensions captured how the sample of co-production cases varied in how they were framed, designed, implemented, supported by certain capacities, and pursued and produced particular outcomes. These findings were then presented in a 13,000-word report and interrogated in an interactive two-day workshop in Colorado, United States (16-17 July 2018) with 14 case contributors and experts in co-production. Participants discussed the content and framing of the dimensions through dynamic exercises, identified if important aspects were missing and elaborated questions and methods for further analysis. A subsequent half-day workshop was held with 15 practitioners/researchers in Cambridge, United Kingdom (9 August 2018) to explore the relevance and framing of the emerging list of dimensions of difference across cases with people who were generally not as familiar with co-production terminology and approaches. A final list of 72 specific dimensions therefore emerged from a rigorous iterative process that inductively identified critical points of difference across all cases.

\section{Secondary analysis based on final analytical dimensions. The final list of 72} dimensions of difference across all cases guided the secondary analysis. The dimensions used in this analysis include different ways that co-production cases were framed (8), designed (16) and implemented (16), capacities that shaped how co-production cases functioned (4), and distinct outcomes that were intended (14) and produced (14). Each of the 14 outcomes were additionally scored on the exten to which they were assessed, if assessment had occurred. If the assessment method was evaluated by the lead author (in consultation with the case contributor) as being too poor of quality to assess particular outcomes, the achievement score was recorded as missing in the dataset. Supplementary Table 4 presents the typical methods that were used to assess outcomes across the cases, including some of the most innovative approaches.

We employed fuzzy-set social science methods ${ }^{70}$ to devise a scoring process to indicate the extent that cases exhibited particular dimensions. Fuzzy sets provide a flexible approach for translating relevant and at times overlapping concepts that emerge from qualitative analysis into a quantitative framework that indicates the extent to which cases exhibit each feature (usually on a scale from 0 to 1$)^{70}$. In this case, we found it was more straightforward to use a seven-point Likert scale to define relevant steps for each dimension and then scored each case for each dimension. This allowed us to document stepwise differences, without needing to provide non-overlapping categories (that is, exhibiting either one dimension or another, rather than some of each) that would lack precise meaning. To maintain a degree of independence of interpretation across all cases, for each of the 32 cases the lead author then reviewed all case documents and interviews an additional time to score each case on a seven-point Likert scale for each of the 72 dimensions. A score of 1 indicated that the case did not exhibit that dimension, whereas a score of 7 indicated that the case highly exhibited that dimension (for example, for the dimension 'intended networks': $1=$ no intention to reshape networks, $7=$ very strong intention to reshape networks).

Qualitative descriptions were recorded to justify each quantitative score, alongside illustrative quotes from case materials that further justified and explained those choices. Each case contributor reviewed and commented on the full set of scores and justifications/quotes to enhance the accuracy of the scoring process. The lead researcher also discussed dimensions that required further explanation with case contributors through a second hour-long Skype call or, in a few cases, email correspondence. Following the revision of all scores and justifications, the lead researcher reviewed the qualitative descriptions for each numerical value of the Likert scales to refine the precise meaning of each distinct step in all of the seven-point Likert scales. Some case scores were then slightly adjusted according to the precise definitions to ensure consistency of the comparative scoring across all cases. The full list of definitions for all seven-point Likert scales used in this analysis are available in Supplementary Tables 2-4. The qualitative descriptions of all dimensions were coded and analysed in comparison with emerging literature on co-production approaches to identify the key dimensions of difference (the four 'Ps'). Quotes also helped explain the patterns that emerged in the statistical analyses.

The production of this study by 42 people, many of whom are leading scholars in co-production and sustainability scholarship and practice, was essential for producing a salient and legitimate output that accurately reflects a rich breadth of co-production experience and perspectives. Moreover, many of the authors both conduct research on as well as practice co-production. Given the diversity of backgrounds, expertise and experiences of the authors who collaboratively produced this study, a key component of the analysis focused on dialogue around different perspectives and approaches to co-production. This facilitated an analytical design that was both rigorous and reflexive, in which all co-authors were able to question their own views of co-production against others and draw collective insights.

Statistical analyses. All statistical analyses and visualizations were done using R version 3.6.1 (ref. ${ }^{71}$ ). Given the large number of descriptive dimensions (36) and outcome dimensions (14 intended and 14 achieved), with substantial missing data for 5 achieved outcomes, we did not seek to determine causal patterns leading to specific outcomes. Rather, we sought to identify important differences in the overall designs/goals of co-production cases, and then use complementary 
quantitative and qualitative analyses to identify key features and broad patterns associated with the full range of outcome dimensions. Our secondary analysis and review of related literature identified four overarching themes (Fig. 2), with two alternate approaches to each, as being particularly important in directing projects towards different types of practice and intended outcomes. These alternate approaches to co-production for each theme are: for purpose, either to more effectively solve predefined problems or to reframe problems; for power, either focusing on the behaviour of actors directly linked to sustainability problems or targeting more systemic aspects; for politics, either empowering marginalized actors or influencing powerful actors to yield power; and for pathways, either by primarily producing scientific knowledge as a product that is expected to shape policy and/or practice or through more integrated forms of knowing, relating and doing.

To identify distinct modes of co-production, we conducted hierarchical cluster analysis using the eight approaches to co-production outlined above (and in Fig. 2). The NbClust ${ }^{72}$ package in $\mathrm{R}$ identified six clusters as the optimal number, based on the peak of the Dindex second differences plot. The R packages tidyverse ${ }^{73}$, cluster $^{74}$, factoextra ${ }^{75}$ and dendextend ${ }^{76}$ were used to conduct the hierarchical cluster analysis, using Euclidean distance as the dissimilarity matrix coefficient and Ward's method of hierarchical clustering to minimize the error in sum of squares ${ }^{58}$. The $\mathrm{R}$ package $\mathrm{fmsb}^{77}$ was used to generate the radar charts displayed in Fig. 3. The R stats package ${ }^{71}$ heatmap function was used to generate visual diagrams to show how case clusters differ (Fig. 4). The qualitative descriptions associated with the scores for each case were also reviewed to help describe each cluster (that is, mode). The qualitative analysis confirmed that all modes were well defined by important differences, and that even though one mode was especially small (mode $3)$, its highly unique nature merited its separation from other modes.

Unique features of each mode were examined by testing for significant differences between mode means for each descriptive dimension, using the stats package $^{71}$ to conduct Kruskal-Wallis tests. Pairwise Wilcoxon signed-rank tests revealed which pairs of modes were significantly different for each dimension. Relatively few significant differences emerged between mode 3 and the other modes due to there being only two cases in that mode. To reduce the large number of descriptive dimensions, principal component analyses were conducted on three different sets of highly intercorrelated dimensions using $\mathrm{R}$ packages stats and ggbiplot ${ }^{78}$. For example, the dimension 'coproduced process' is a principal component that explains $82.1 \%$ of the variance of the extent to which the case was co-designed and co-practiced. Similarly, the dimension 'supportive context' explains $81.5 \%$ of the variance for two dimensions that indicate how well cases were supported by external funding and other contextual dynamics. Finally, the dimension 'expertly facilitated' explains $57.3 \%$ of the variance of nine highly intercorrelated dimensions related to the extent that cases organized roles, facilitated knowledge and navigated issues of conflict and power.

The R packages qgraph ${ }^{79}$, SemiPar ${ }^{80}$ and $\mathrm{Hmisc}^{81}$ were used to visualize correlation networks among the eight key dimensions (Fig. 2). To explore correlations between achieved outcomes, we calculated Spearman's rank correlation coefficients and their $P$ values. For intended outcomes, we used the direct seven-point Likert scale scores (Supplementary Table 4). However, this was not possible for achieved outcomes because the meaning of an outcome that was highly achieved (that is, score $=7$ ) greatly varied for a case that highly intended that outcome versus one that weakly intended it and conducted few related activities. To calculate each achieved outcome, we therefore multiplied the extent to which it was achieved (for example, score of $5=5 / 7$ ) by the intention score (for example, $5)$. In this way, a moderately achieved outcome that was highly intended was made equivalent to a moderately intended outcome that was highly achieved. To identify the list of 9 descriptive dimensions significantly correlated to achieving outcomes across the board, we used the mean of 11 outcome dimensions, as 3 outcomes had insufficient data across cases.

Ethics. The institution that hosted this study (Luc Hoffmann Institute) does not have a formal research ethics approval process; however, we nevertheless developed our own procedure for this project, which complied with the Department of Geography Ethics Review Group guidelines at the University of Cambridge. Furthermore, all interviewees of this study are also co-authors on this manuscript, so they were involved in the decisions made throughout the entire process related to ethical concerns, with active steps taken to recognize their individual contributions and to protect the confidentiality of their data. Each case contributor additionally communicated with the main proponents of their initiative to seek informed consent for the inclusion of the case in this research. In the majority of cases, case contributors were themselves a main project proponent, although in some cases they had extensively researched it.

Reporting Summary. Further information on research design is available in the Nature Research Reporting Summary linked to this article.

\section{Data availability}

The data analysed in this study can be made available upon request, with a few limitations. Quantitative data on outcomes cannot be shared at the level of individual cases because some projects are still ongoing and some projects have not met their anticipated outcomes; thus, sharing this data could negatively impact projects and their participants. However, complete quantitative data can be provided at the level of each of the six modes, keeping the specific case identities anonymous. In addition, qualitative codes can be shared to provide further details of the qualitative analytical process. At the level of individual cases, if people wish to access data for a specific case, they will be put in touch with the contributor of that case (also a co-author of this manuscript), who must be informed of the data being requested and the intended use for it. Each case contributor will then provide the final say on whether they wish to share their own quantitative and qualitative case data on a case-by-case basis. These protective steps were critical for ensuring a safe environment for case contributors to share many critical perspectives related to the challenges and outcomes of their cases, thereby ensuring an ethical analysis with accurate results.

\section{Code availability}

The codes used in $\mathrm{R}$ to produce all statistics and figures can be made available upon request.

Received: 5 June 2020; Accepted: 6 July 2021;

Published online: 05 August 2021

\section{References}

1. Wyborn, C. et al. Co-producing sustainability: reordering the governance of science, policy, and practice. Annu. Rev. Environ. Resour. 44, 319-346 (2019).

2. Verschuere, B., Brandsen, T. \& Pestoff, V. Co-production: the state of the art in research and the future agenda. Voluntas 23, 1083-1101 (2012).

3. Miller, C. A. \& Wyborn, C. Co-production in global sustainability: histories and theories. Environ. Sci. Policy 113, 88-95 (2018).

4. Bremer, S. \& Meisch, S. Co-production in climate change research: reviewing different perspectives. Wiley Interdiscip. Rev. Clim. Change 8, e482 (2017).

5. Clark, W. C., Kerkhoff, L., van Lebel, L. \& Gallopin, G. C. Crafting usable knowledge for sustainable development. Proc. Natl Acad. Sci. USA 113, 4570-4578 (2016).

6. Chen, J.-S., Tsou, H.-T. \& Ching, R. K. H. Co-production and its effects on service innovation. Ind. Mark. Manage. 40, 1331-1346 (2011).

7. Lemos, M. C. et al. To co-produce or not to co-produce. Nat. Sustain. 1, $722-724$ (2018)

8. Bodin, Ö. Collaborative environmental governance: achieving collective action in social-ecological systems. Science 357, eaan1114 (2017).

9. Norström, A. V. et al. Principles for knowledge co-production in sustainability research. Nat. Sustain. 3, 182-190 (2020).

10. Sorrentino, M., Sicilia, M. \& Howlett, M. Understanding co-production as a new public governance tool. Policy Soc. 37, 277-293 (2018)

11. Slater, K. \& Robinson, J. Social learning and transdisciplinary co-production: a social practice approach. Sustainability 12, 7511 (2020).

12. Page, G. G. et al. Co-designing transformation research: lessons learned from research on deliberate practices for transformation. Curr. Opin. Environ. Sustain. 20, 86-92 (2016).

13. Knapp, C. N., Reid, R. S., Fernández-Giménez, M. E., Klein, J. A. \& Galvin, K. A. Placing transdisciplinarity in context: a review of approaches to connect scholars, society and action. Sustainability 11, 4899 (2019).

14. Mauser, W. et al. Transdisciplinary global change research: the co-creation of knowledge for sustainability. Curr. Opin. Environ. Sustain. 5, 420-431 (2013).

15. Polk, M. Transdisciplinary co-production: designing and testing a transdisciplinary research framework for societal problem solving. Futures 65, 110-122 (2015)

16. Cockburn, J., Cundill, G., Shackleton, S. \& Rouget, M. Towards placebased research to support social-ecological stewardship. Sustainability 10, 1434 (2018)

17. Musch, A.-K. \& von Streit, A. (Un)intended effects of participation in sustainability science: a criteria-guided comparative case study. Environ. Sci. Policy 104, 55-66 (2020).

18. van der Hel, S. New science for global sustainability? The institutionalisation of knowledge co-production in Future Earth. Environ. Sci. Policy 61, 165-175 (2016)

19. Harvey, B., Cochrane, L. \& Epp, M. V. Charting knowledge coproduction pathways in climate and development. Environ Policy Gov. 29, 107-117 (2019)

20. van Kerkhoff, L. E. \& Lebel, L. Coproductive capacities: rethinking science-governance relations in a diverse world. Ecol. Soc. 20, 14 (2015).

21. Turnhout, E., Metze, T., Wyborn, C., Klenk, N. \& Louder, E. The politics of co-production: participation, power, and transformation. Curr. Opin. Environ. Sustain. 42, 15-21 (2020).

22. Järvi, H., Kähkönen, A.-K. \& Torvinen, H. When value co-creation fails: reasons that lead to value co-destruction. Scand. J. Manage. 34, 63-77 (2018).

23. Schneider, F. et al. Transdisciplinary co-production of knowledge and sustainability transformations: three generic mechanisms of impact generation. Environ. Sci. Policy 102, 26-35 (2019). 
24. Jagannathan, K. et al. Great expectations? Reconciling the aspiration, outcome, and possibility of co-production. Curr. Opin. Environ. Sustain. 42 22-29 (2020).

25. Newig, J., Jahn, S., Lang, D. J., Kahle, J. \& Bergmann, M. Linking modes of research to their scientific and societal outcomes. Evidence from 81 sustainability-oriented research projects. Environ. Sci. Policy 101, 147-155 (2019).

26. Seijger, C., Dewulf, G., van Tatenhove, J. \& Otter, H. S. Towards practitioner-initiated interactive knowledge development for sustainable development: a cross-case analysis of three coastal projects. Glob. Environ. Change 34, 227-236 (2015).

27. Malinauskaite, L., Cook, D., Davíðsdóttir, B. \& Ögmundardóttir, H. in Nordic Perspectives on the Responsible Development of the Arctic: Pathways to Action (ed. Nord, D. C.) 181-202 (Springer, 2021).

28. Oteros-Rozas, E. et al. Participatory scenario planning in place-based social-ecological research: insights and experiences from 23 case studies. Ecol. Soc. 20, 32 (2015).

29. Pereira, L. et al. Transformative spaces in the making: key lessons from nine cases in the global south. Sustain. Sci. 15, 161-178 (2019).

30. Flyvbjerg, B. Five misunderstandings about case-study research. Qual. Inq. 12, 219-245 (2006).

31. Haller, T., Acciaioli, G. \& Rist, S. Constitutionality: conditions for crafting local ownership of institution-building processes. Soc. Nat. Resour. 29, 68-87 (2016).

32. Brennan, R. E. Re-storying marine conservation: integrating art and science to explore and articulate ideas, visions and expressions of marine space. Ocean Coast. Manage. 162, 110-126 (2018).

33. Dumrongrojwatthana, P. \& Trébuil, G. in Knowledge in Action Vol. 11 (eds van Paassen, A. et al.) 191-219 (Wageningen Academic, 2011).

34. Steyaert, P. \& Jiggins, J. Governance of complex environmental situations through social learning: a synthesis of SLIM's lessons for research, policy and practice. Environ. Sci. Policy 10, 575-586 (2007).

35. Goldstein, B. E. et al. Transformative learning networks. In Proc. 60th Annual Meeting of the International Society for the Systems Sciences (ISSS) (2018).

36. Österblom, H., Jouffray, J.-B., Folke, C. \& Rockström, J. Emergence of a global science-business initiative for ocean stewardship. Proc. Natl Acad. Sci. USA 114, 9038-9043 (2017)

37. Christie, P. et al. Why people matter in ocean governance: incorporating human dimensions into large-scale marine protected areas. Mar. Policy 84, 273-284 (2017).

38. Brandeis, A. in River Basin Restoration and Management (eds Ostfeld, A. \& Tyson, J. M.) 3-13 (IWA, 2005).

39. Chatterton, P., Owen, A., Cutter, J., Dymski, G. \& Unsworth, R. Recasting urban governance through Leeds City Lab: developing alternatives to neoliberal urban austerity in co-production laboratories. Int. J. Urban Reg. Res. 42, 226-243 (2018).

40. Hill, R. et al. Knowledge co-production for Indigenous adaptation pathways transform post-colonial articulation complexes to empower local decision-making. Glob. Environ. Change 65, 102161 (2020).

41. Mitchell, M. et al. The Montérégie Connection: linking landscapes, biodiversity, and ecosystem services to improve decision making. Ecol. Soc. 20, 15 (2015).

42. Gerber, J.-D. Regional nature parks in Switzerland. Between top-down and bottom-up institution building for landscape management. Hum. Ecol. 46, 65-77 (2018).

43. Reid, R. S. et al. Evolution of models to support community and policy action with science: balancing pastoral livelihoods and wildlife conservation in savannas of East Africa. Proc. Natl Acad. Sci. USA. 113, 4579-4584 (2016).

44. Charli-Joseph, L., Siqueiros-Garcia, J. M., Eakin, H., Manuel-Navarrete, D. \& Shelton, R. Promoting agency for social-ecological transformation: a transformation-lab in the Xochimilco social-ecological system. Ecol. Soc. 23, 46 (2018).

45. Montana, J., Sandbrook, C., Robertson, E. \& Ryan, M. Revealing research preferences in conservation science. Oryx 55, 404-411 (2019).

46. Lövbrand, E. Co-producing European climate science and policy: a cautionary note on the making of useful knowledge. Sci. Public Policy 38, 225-236 (2011).

47. Barnett, M. \& Duvall, R. Power in international politics. Int. Organ. 59, 39-75 (2005).

48. Abson, D. J. et al. Leverage points for sustainability transformation. Ambio 46, 30-39 (2017).

49. Giddens, A. The Constitution of Society: Outline of the Theory of Structuration (Polity Press, 1984).

50. Leimona, B. et al. Boundary work: knowledge co-production for negotiating payment for watershed services in Indonesia. Ecosyst. Serv. 15, 45-62 (2015).

51. Brandt, F., Josefsson, J. \& Spierenburg, M. J. Power and politics in stakeholder engagement: farm dweller (in)visibility and conversions to game farming in South Africa. Ecol. Soc. 23, 32 (2018).
52. Avelino, F. Power in sustainability transitions: analysing power and (dis) empowerment in transformative change towards sustainability. Environ. Policy Gov. 27, 505-520 (2017).

53. Lasswell, H. D. Politics: Who Gets What, When, How (McGraw-Hill, 1936).

54. Cockburn, J. et al. How to build science-action partnerships for local land-use planning and management: lessons from Durban, South Africa. Ecol. Soc. 21, 28 (2016).

55. Nagendra, $\mathrm{H}$. The global south is rich in sustainability lessons that students deserve to hear. Nature 557, 485-488 (2018).

56. Turnheim, B. et al. Evaluating sustainability transitions pathways: bridging analytical approaches to address governance challenges. Glob. Environ. Change 35, 239-253 (2015).

57. Nel, J. L. et al. Knowledge co-production and boundary work to promote implementation of conservation plans. Conserv. Biol. 30, 176-188 (2016).

58. Ward, J. H. Hierarchical grouping to optimize an objective function. J. Am. Stat. Assoc. 58, 236-244 (1963).

59. Fernández-Giménez, M. E. et al. in Collaboration Across Boundaries for Social-Ecological Systems Science: Experiences Around the World (ed. Perz, S. G.) $185-225$ (Springer, 2019).

60. van Kerkhoff, L. et al. Towards future-oriented conservation: managing protected areas in an era of climate change. Ambio 48, 699-713 (2019).

61. Lejano, R. P. \& Ingram, H. Collaborative networks and new ways of knowing Environ. Sci. Policy 12, 653-662 (2009).

62. Clark, W. C. et al. Boundary work for sustainable development: natural resource management at the Consultative Group on International Agricultural Research (CGIAR). Proc. Natl Acad. Sci. USA 113, 4615-4622 (2016).

63. Reed, M. S. et al. A theory of participation: what makes stakeholder and public engagement in environmental management work? Restor. Ecol. 26, S7-S17 (2018)

64. Belcher, B. M., Claus, R., Davel, R. \& Ramirez, L. F. Linking transdisciplinary research characteristics and quality to effectiveness: a comparative analysis of five research-for-development projects. Environ. Sci. Policy 101, 192-203 (2019).

65. Wuelser, G. \& Pohl, C. How researchers frame scientific contributions to sustainable development: a typology based on grounded theory. Sustain. Sci. 11, 789-800 (2016).

66. Van Epp, M. \& Garside, B. Towards an evidence base on the value of social learning-oriented approaches in the context of climate change and food security. Environ. Policy Gov. 29, 118-131 (2019).

67. Harvey, L. Beyond member-checking: a dialogic approach to the research interview. Int. J. Res. Method Educ. 38, 23-38 (2015).

68. Fazey, I. et al. Transforming knowledge systems for life on Earth: visions of future systems and how to get there. Energy Res. Soc. Sci. 70, 101724 (2020).

69. Urquhart, C. Grounded Theory for Qualitative Research: A Practical Guide (SAGE, 2012).

70. Ragin, C. C. Fuzzy-Set Social Science (Univ. Chicago Press, 2000).

71. R Core Team R: A Language and Environment for Statistical Computing (R Foundation for Statistical Computing, 2019).

72. Charrad, M., Ghazzali, N., Boiteau, V. \& Niknafs, A. NbClust: an R package for determining the relevant number of clusters in a data set. J. Stat. Softw. 61, 36 (2014).

73. Wickham, H. et al. Welcome to the tidyverse. J. Open Source Softw. 4, 1686 (2019).

74. Maechler, M., Rouseeuw, P., Struyf, A., Hubert, M. \& Hornik, K. cluster: Cluster Analysis Basics and Extensions (2019).

75. Kassambara, A. \& Mundt, F. Factoextra: Extract and Visualize the Results of Multivariate Data Analyses (2017).

76. Galili, T. dendextend: an R package for visualizing, adjusting and comparing trees of hierarchical clustering. Bioinformatics 31, 3718-3720 (2015).

77. Nakazawa, M. Package 'fmsb': Functions for Medical Statistics Book with some Demographic Data (2019).

78. Vu, V. Q. ggbiplot: A ggplot2 Based Biplot. R package version 0.55 (2011).

79. Epskamp, S., Cramer, A. O. J., Waldorp, L. J., Schmittmann, V. D. \& Borsboom, D. qgraph: network visualizations of relationships in psychometric data. J. Stat. Softw. 48, 18 (2012).

80. Wand, M. et al. SemiPar: An R Package for Semiparametric Regression. Version 1.0. (2005); http://matt-wand.utsacademics.info/SPmanu.pdf 81. Harrell, F. E. Jr Hmisc: Harrell Miscellaneous. Version 4.3-0 (2019).

\section{Acknowledgements}

This project and paper were supported by the Luc Hoffmann Institute and MAVA Foundation. We acknowledge the Center for Collaborative Conservation, PECS, the Cambridge Conservation Initiative and The Pew Charitable Trusts for hosting our workshops. We thank J. Lokrantz at Azote for improving the graphics design. J.M.C. received support from the Economic and Social Research Council (grant RG97777). J.J.C. was funded by a Rhodes University Postdoctoral Fellowship and acknowledges the contributions of P. Singh and S. Behngu to analysing the Durban Research Action Partnership case. H.Ö. was funded by the Walton Family Foundation (grant 2018-1371), the David and Lucile Packard Foundation (grant 2019-68336) and the Gordon and Betty 
Moore Foundation (grant GBMF5668.02). J.M.H.G. was supported by the UK Research and Innovation's Global Challenges Research Fund through the Trade, Development and the Environment Hub project (project ES/S008160/1). A.-I.H.-M. was supported from a Volkswagen Stiftung and the Niedersächsisches Ministerium für Wissenschaft und Kultur grant (A112269), followed by a Marie Sklodowska-Curie grant (840207). A.-I.H.-M also acknowledges support from the Leverage Points project practice partners and all project team members. J.M. was supported by the Leverhulme Trust. J.G.Z. was funded by the r4d programme of the Swiss Programme for Research on Global Issues for Development (grant 400440 152167). Elements of this work were undertaken while J.G.Z. was a visiting scholar at the Department of Geography, University of Cambridge (May 2018-April 2019), supported through Scientific Exchange funding from the Swiss National Science Foundation (grant IZSEZ0_180391).

\section{Author contributions}

J.M.C., C.W. and M.E.R. conceived the project and co-led the design of methods, with contributions from R.S.R., M.R., A.S., N.J.B., C.C., M.E.F.-G., K.A.G., B.E.G., N.L.K., M.T., A.T.B., K.C., R.G. and T.P. Authors J.M.C., M.E.R., C.W., R.S.R. and A.T.B organized and designed all workshops. J.M.C. coordinated the study, gathered all data and led the data analysis in collaboration with all authors. J.M.C. and C.W. drafted the manuscript and all authors contributed to and commented on drafts and the final version.

\section{Competing interests}

The authors declare no competing interests.

\section{Additional information}

Supplementary information The online version contains supplementary material available at https://doi.org/10.1038/s41893-021-00755-x.

Correspondence and requests for materials should be addressed to J.M.C.

Peer review information Nature Sustainability thanks William C. Clark, Catherine Durose and the other, anonymous, reviewer(s) for their contribution to the peer review of this work

Reprints and permissions information is available at www.nature.com/reprints.

Publisher's note Springer Nature remains neutral with regard to jurisdictional claims in published maps and institutional affiliations.

(c) The Author(s), under exclusive licence to Springer Nature Limited 2021 


\section{Reporting Summary}

Nature Research wishes to improve the reproducibility of the work that we publish. This form provides structure for consistency and transparency in reporting. For further information on Nature Research policies, see our Editorial Policies and the Editorial Policy Checklist.

\section{Statistics}

For all statistical analyses, confirm that the following items are present in the figure legend, table legend, main text, or Methods section.

n/a Confirmed

$\bigotimes$ The exact sample size $(n)$ for each experimental group/condition, given as a discrete number and unit of measurement

$\square$ A statement on whether measurements were taken from distinct samples or whether the same sample was measured repeatedly

$\square$ The statistical test(s) used AND whether they are one- or two-sided

$\square$ Only common tests should be described solely by name; describe more complex techniques in the Methods section.

$\square$ \ A description of all covariates tested

$\square$ \A description of any assumptions or corrections, such as tests of normality and adjustment for multiple comparisons

$\square$ A full description of the statistical parameters including central tendency (e.g. means) or other basic estimates (e.g. regression coefficient)

AND variation (e.g. standard deviation) or associated estimates of uncertainty (e.g. confidence intervals)

$\bigotimes \square \begin{aligned} & \text { For null hypothesis testing, the test statistic (e.g. } F, t, r \text { ) with confidence intervals, effect sizes, degrees of freedom and } P \text { value noted } \\ & \text { Give } P \text { values as exact values whenever suitable. }\end{aligned}$

\ $\square$ For Bayesian analysis, information on the choice of priors and Markov chain Monte Carlo settings

$\square$ \ For hierarchical and complex designs, identification of the appropriate level for tests and full reporting of outcomes

$\square \bigotimes$ Estimates of effect sizes (e.g. Cohen's $d$, Pearson's $r$ ), indicating how they were calculated

Our web collection on statistics for biologists contains articles on many of the points above.

\section{Software and code}

Policy information about availability of computer code

Data collection No code was used to collect data.

Data analysis R code was used to conduct all statistical analyses and can be made available to editors or reviewers of Nature Sustainability, upon request. For manuscripts utilizing custom algorithms or software that are central to the research but not yet described in published literature, software must be made available to editors and reviewers. We strongly encourage code deposition in a community repository (e.g. GitHub). See the Nature Research guidelines for submitting code \& software for further information.

\section{Data}

Policy information about availability of data

All manuscripts must include a data availability statement. This statement should provide the following information, where applicable:

- Accession codes, unique identifiers, or web links for publicly available datasets

- A list of figures that have associated raw data

- A description of any restrictions on data availability

There are no specific requirements by our funders to make our data publicly available, however we recognize the importance of transparency and contributing to additional research that builds on our work. We have therefore included a data availability statement in the manuscript that seeks to balance our concerns with protecting the confidentiality of sensitive data related to individual cases and their outcomes, with making our data as openly accessible as possible. We will make data available upon request at the level of each of the six clusters, keeping case identities anonymous. If people wish to access specific data for one or more of our 32 cases, they must provide a request to the specific contributor (and co-author) of that case, who will make the final call on whether they wish to provide the requested data for the intended purpose. These data availability measures are essential to ethically handle the sensitive nature of data which very openly discusses challenges and failed outcomes (in some cases) related to these projects. These measures were also critical to guaranteeing the accuracy of our critical analysis of each case, and thus the validity of our overall findings. 


\section{Field-specific reporting}

Please select the one below that is the best fit for your research. If you are not sure, read the appropriate sections before making your selection.

Life sciences

Behavioural \& social sciences

Ecological, evolutionary \& environmental sciences

For a reference copy of the document with all sections, see nature.com/documents/nr-reporting-summary-flat.pdf

\section{Behavioural \& social sciences study design}

All studies must disclose on these points even when the disclosure is negative.

Study description

The data are mixed method, and include qualitative descriptions of how the 32 initiatives using collaborative approaches for sustainability differ for 72 dimensions. These 72 dimensions were defined based on in-depth qualitative analysis. Each case was then quantitatively judged on a 7-point likert scale to indicate the extent they express each of the dimensions, based on fuzzy-set social science methods and providing qualitative justifications that were then validated by each case contributor. Quantitative data were then used to conduct statistical analyses, and the patterns were interpreted through additional qualitative analyses.

Research sample $\quad 32$ collaborative initiatives were selected for this study, with the aim to maximize diversity in both approach and geographical and scalar context. We achieved this diversity, with cases applying a wide range of research methodologies spanning fields such as ecology, social science, art and engineering, and involving in most cases, at least four types of stakeholders (e.g. academia, government, NGOs, communities). Cases also operated in six different continents, with at least 3 different cases in each continent, and the majority operated at multiple scales, from local to international. The cases were more heavily led by research institutes. Our study did not rely on existing data sets and collaborated closely with a single person heavily involved in each case study in order to gather information through documents and interviews.

Sampling strategy

The 32 cases were selected from the initial workshops, only including cases that had been running for longer than 2 years and focused on sustainability challenges $(n=8)$, and through Google Scholar $(n=24)$. The latter were identified by individually pairing 10 variants of the term 'conservation' such as 'ecosystem services' and 'marine conservation' with 22 variants of collaboration such as 'co-production', 'co-design', 'co-management', 'social learning' and 'participatory action research'. We used this approach to select a set of cases that encompassed the diversity we found, although our sampling approach is biased towards international researchers, as their work is more likely to be highly cited and we did not review grey literature. It was also difficult to engage diverse local projects with non-English speakers that do not have international networks. We therefore actively sought to include cases from a diverse range of contexts, with multiple cases in each broad geographical region, to incorporate some degree of cultural diversity. We included a total of 32 cases because we wanted to achieve a sample size sufficient for quantitative comparisons across cases, but also wanted to keep the number low enough to analyze a high level of qualitative depth per case.

Data collection

Data was collected by collaborating with each case contributor. Each contributor sent relevant materials to learn about their cases and the lead author interviewed each contributor twice over skype. For all interviews, the conversation was recorded and transcribed (with the permission of the interviewee). The interviews and materials were then used to fill quantitative and qualitative data into an excel spreadsheet template with 72 dimensions that were identified as being interesting from the participatory workshops and literature review. Each case contributor reviewed the spreadsheet pertaining to their case to validate the data, and small revisions were made, as necessary. The data from participatory workshops was recorded by the participants themselves as they wrote their ideas onto post-it notes and large pieces of papers, and then image files of these materials were stored.

Timing

The initial scoping workshops took place in May and November of 2017. All data was collected on the 32 cases during February-July 2018, followed by two additional participatory workshops in July and August, 2018. Further data was collected about each case during August 2018 - October 2019 to complete the secondary analysis, as it took at least a week to collect and analyze each case in depth in relation to the 72 dimensions.

Data exclusions

Additional information was collected for each case beyond the 72 dimensions listed in this manuscript; however, we only included the data that was relevant to this particular analysis. For example, we also collected data on underlying rationales expressed for why particular decisions were made to undertake collaboration in particular ways; however, this excluded data is being used to produce a second paper for a different journal.

Non-participation

Three people who were asked to contribute their cases decided not to participate in the study. One person did not want to share her case information because she first wanted to produce her own publications, and two people did not have enough time to contribute.

\section{Reporting for specific materials, systems and methods}

We require information from authors about some types of materials, experimental systems and methods used in many studies. Here, indicate whether each material, system or method listed is relevant to your study. If you are not sure if a list item applies to your research, read the appropriate section before selecting a response. 


\begin{tabular}{l|l|l}
\hline n/a & Involved in the study \\
\hline & $\square$ Antibodies \\
\hline & $\square$ Eukaryotic cell lines \\
\hline & $\square$ Animalaeontology and archaeology \\
$\square$ & $\square$ Clinical data \\
\hline Dual use research of concern
\end{tabular}

\begin{tabular}{l|l}
\hline n/a & Involved in the study \\
$\bigotimes$ & $\square$ ChIP-seq \\
$\searrow$ & $\square$ Flow cytometry \\
$\bigotimes$ & $\square$ MRI-based neuroimaging
\end{tabular}

\section{Human research participants}

Policy information about studies involving human research participants

Population characteristics

Recruitment

Ethics oversight

\section{See above.}

See above. Cases were specifically selected to maximize diversity, including from 8 cases of $2+$ years that self-selected into our workshops, as well as 24 cases we identified based on a broader search using google scholar in order to maximize diversity within the sample. The most important source of bias, is that we studied collaborations where researchers were more highly represented in leadership positions, related to our reliance on published academic literature to find cases. We also ended up with more leaders of collaborative initiatives from the global North, despite the very high geographic diversity of project locations. We have clearly elaborated both of these biases in the manuscript. Nevertheless, we are still examining a much greater diversity of cases, approaches and locations than we have seen to date in the literature.

A statement is provided in the manuscript, which indicates that we complied with the Department of Geography Ethics Review Group guidelines. This choice was made because the institute which hosted this research (Luc Hoffmann Institute) did not have a formal ethical review process, but it was very important to us that the methods are well informed by appropriate ethical guidance. These specific guidelines were selected, as the lead author was also connected to this institute during this project. It is also important to mention that all human participants in this work are also co-authors, so they have been deeply involved in the entire research process, and have also shaped decisions of how to best handle the data and recognize contributions in an ethical manner. 